\title{
Geologia do Granito Três Figueiras: magmatismo peraluminoso de 585 Ma no sudeste do Cinturão Dom Feliciano
}

\author{
Fernando Galvão KLEIN ${ }^{1}$, Edinei KOESTER ${ }^{1,2}$, Daniel Triboli VIEIRA ${ }^{1}$, Rodrigo Chaves RAMOS ${ }^{1}$, \\ Carla Cristine PORCHER ${ }^{1,2}$ \& Ruy Paulo PHILIPP ${ }^{1,3}$
}

1 Programa de Pós-Graduação em Geociências, Instituto de Geociências, Universidade Federal do Rio Grande do Sul. Caixa Postal 15.001, CEP 91501-970, Porto Alegre, RS, Brasil (fergklein@gmail.com, danieltriboli@hotmail.com, rodrigo.chaves@ufrgs.br).

2 Departamento de Geologia, Instituto de Geociências, Universidade Federal do Rio Grande do Sul. Caixa Postal 15.001, CEP 91501-970, Porto Alegre, RS, Brasil (koester@ufrgs.br, carla.porcher@ufrgs.br).

3 Departamento de Mineralogia e Petrologia, Instituto de Geociências, Universidade Federal do Rio Grande do Sul. Caixa Postal 15.001, CEP 91501-970, Porto Alegre, RS, Brasil (ruy.philipp@ufrgs.br).

Klein, F.G., Koester, E., Vieira, D.T., Ramos, R.C., Porcher, C.C, \& Philipp, R.P. 2018. Geologia do Granito Três Figueiras: magmatismo peraluminoso de 585 Ma no sudeste do Cinturão Dom Feliciano. Pesquisas em Geociências, 46: e0665.

DOI: https://doi.org/10.22456/1807-9806.88646

Resumo. O Granito Três Figueiras representa a única ocorrência de granitos peraluminosos no extremo sudeste do Cinturão Dom Feliciano, Rio Grande do Sul. Este tipo de granito pode conter informações importantes a respeito do ambiente tectônico e evolução tectônica e termal de um cinturão orogênico. 0 objetivo deste trabalho é a caracterização geológica do Granito Três Figueiras, com base em dados de campo, geologia estrutural, petrografia, geoquímica e geocronologia. 0 granito é cinza claro, composto por quartzo, K-feldspato, plagioclásio, muscovita, biotita (M' 7-10), com granada, turmalina, zircão, monazita e apatita como minerais acessórios. É um granito sincinemático à Zona de Cisalhamento Arroio Grande, onde desenvolve uma trama milonítica com foliação tectônica subvertical com mergulho $>70^{\circ}$ para SE e lineação de estiramento sub-horizontal marcada pelas micas e agregados estirados de quartzo e feldspato, com direção N80E e caimento de até $10^{\circ}$ para ENE, que demonstram o caráter transcorrente desta zona. As microestruturas e texturas indicam temperaturas de deformação de pelo menos $550^{\circ} \mathrm{C}$ e cinemática dextral para esta zona de cisalhamento. 0 granito é classificado como peraluminoso, com teores de A/CNK entre 1,07 e 1,21 e coríndon normativo entre 1,2 a $3 \%$. Possui altos teores de $\mathrm{SiO}_{2}, \mathrm{Al}_{2} \mathrm{O}_{3}$, álcalis, e baixos teores de $\mathrm{FeO}$, $\mathrm{MgO}$ e $\mathrm{TiO}_{2}$. Apresenta correlação negativa para a maioria dos elementos maiores, o que indica que o principal processo de evolução magmática foi cristalização fracionada. Uma fonte homogênea é sugerida a partir da relação entre elementos traços e ETR. Com a datação U-Pb se obteve uma idade de cristalização magmática de $585 \pm 16 \mathrm{Ma}$, que registra um importante evento de fusão crustal para o extremo sudeste do Cinturão Dom Feliciano.

Palavras-chave. Petrologia, Geoquímica, U-Pb, SHRIMP

\begin{abstract}
Geology of the Três Figueiras Granite: Peraluminous Magmatism at 585 MA IN SouTHEASTERN Dom FELICIANo BELT. The Três Figueiras Granite represents an unique occurrence of peraluminous granite in the southeastern Dom Feliciano Belt. Peraluminous granite may contain important data about the tectonic environment and thermal evolution of an orogenic belt. The main goal of this work is to present the geologic characterization of the Três Figueiras Granite, based on field data, structural geology, petrography, geochemistry and geochronology. The granite is light grey coloured composed of quartz, K-feldspar, plagioclase, muscovite, biotite (M' 7-10), with garnet, tourmaline, zircon, monazite and apatite as accessory minerals. It is synkinematic to the Arroio Grande Shear Zone, where it develops a mylonitic fabric with subvertical tectonic foliation with dip $>70^{\circ}$ for SE and a stretching lineation marked by elongated micas and aggregates of quartz and feldspar, both with a $\mathrm{N} 80^{\circ} \mathrm{E}$ trend dipping $10^{\circ}$ ENE. The observed microstructures and textures show deformation temperature of at least $550{ }^{\circ} \mathrm{C}$ and dextral kinematic. It is classified as a peraluminous granite with $\mathrm{A} / \mathrm{CNK}$ content ranging between 1.07 and 1.21 and normative corundum from 1.2 to $3 \%$. It has high $\mathrm{SiO}_{2}, \mathrm{Al}_{2} \mathrm{O}_{3}$ and alkalis $\left(\mathrm{K}_{2} \mathrm{O}+\mathrm{NaO}\right)$ and low $\mathrm{FeO}, \mathrm{MgO}$ and $\mathrm{TiO}_{2}$ contents. In Harker diagrams the granite shows negative correlation for most of the major elements in response to the fractional crystallization process. Multi-element diagrams indicate an uniform source for the entire
\end{abstract}


set of the analyzed samples. Zircon U-Pb SHRIMP dating yielded an age of $585 \pm 16 \mathrm{Ma}$, interpreted as magmatic crystallization an important record of Neoproterozoic peraluminous magmatism in the southeastern portion of the Eastern Domain of Dom Feliciano Belt.

Keywords. Petrology, Geochemistry, U-Pb, SHRIMP

\section{Introdução}

Rochas graníticas de natureza peraluminosa estão presentes em muitos cinturões orogênicos, de idades variadas, desde o Pré-cambriano até o Fanerozoico (White \& Chappell, 1977; Barbarin, 1996). Diversos trabalhos tratam da importância e discutem a formação destas rochas com base em critérios como a composição da fonte (Chappell \& White, 1974 e 1992), ambiente tectônico relacionado (Pitcher, 1983; Pearce et al., 1984; Barbarin, 1990 e 1996), ou com base em processos de diferenciação magmática (Wilson, 1989). De modo geral, granitos peraluminosos são denominados granitos tipo S (White \& Chappell, 1977), cujas implicações tectônicas estão associadas a ambientes colisionais, sendo considerados granitos de fusão crustal (Pitcher, 1983; Barbarin, 1996; PatiñoDouce, 1999), ou tipo I, com origem relacionada à fusão de rochas ígneas (Pérez-Soba \& Villaseca, 2010).

Conforme Barbarin (1999) os granitos peraluminosos podem ser divididos em MPG (muscovite-bearing peraluminous granitoids) e CPG (cordierite-bearing peraluminous granitoids). MPG são granitos a duas micas, com presença de muscovita primária, podendo conter minerais acessórios como turmalina, granada e monazita. Geralmente são rochas com poucos enclaves que, quando presentes, costumam ser xenólitos da rocha encaixante, margens resfriadas ou restitos. Exemplos deste tipo de granito podem ser encontrados no cinturão herciniano do oeste europeu (De La Roche et al., 1980; Lameyre, 1980) e nos leucogranitos himalaianos (Le Fort, 1981). Os CPG constituem granitoides peraluminosos com presença de cordierita, podendo ser abundante e estar associada com silimanita e, mais raramente, andaluzita. Estes granitoides podem hospedar enclaves restíticos ricos em mica ou máficos microgranulares, principalmente em zonas mais profundas quando relacionados com rochas metamórficas de alto grau. Exemplos destes granitoides podem ser encontrados no Lachlan Fold Belt (White \& Chappell, 1983).
Com relação à origem de magmas peraluminosos, estes são quimicamente discriminados por teores de A/CNK > 1 (Shand, 1943) e presença de coríndon normativo. Os MPG e CPG são granitos de origem crustal, de modo que suas principais diferenças químicas estão relacionadas com o caráter peraluminoso destes magmas, que apresentam tendências de aumento da peraluminosidade com a diferenciação para o MPG, enquanto decresce ou aumenta levemente para os CPG (Barbarin, 1999).

Granitos peraluminosos, produtos de fusões em ambientes colisionais, são produzidos onde há espessamento crustal durante a colisão entre continentes, sendo sua gênese controlada não apenas pela natureza da fonte, mas também pelas condições de anatexia crustal destes ambientes (Barbarin, 1996). Nesse sentido, os MPG se formam quando há anatexia favorecida por zonas de cisalhamento de grande escala e tendem a se hospedar em zonas transcorrentes ou de empurrão, enquanto os tipo CPG são produzidos por underplating ou injeções locais de material derivado do manto e tendem a se dispersar pelo cinturão montanhoso ou estarem relacionados com rochas metamórficas de alto grau na raiz destes cinturões (Barbarin, 1999).

Rochas da crosta continental como metapelitos e quartzo-feldspáticas começam a fundir parcialmente a temperaturas de $650{ }^{\circ} \mathrm{C}$ gerando um líquido de composição granítica. Se haverá ou não fusão e a quantidade de material gerado depende da quantidade de água disponível. Desta forma, as rochas podem fundir quando o conteúdo de $\mathrm{H}_{2} \mathrm{O}$ está ocupando os poros e limites de grãos como um líquido livre a temperaturas mais baixas por um processo denominado fluid-present melting (fusão na presença de fluido), ou por fusão incongruente pela quebra de minerais hidratados como biotita, muscovita e anfibólio. Considerando-se que rochas cristalinas possuem baixa porosidade e são pouco hidratadas, os produtos de fusão neste caso gerariam um volume de magma pouco expressivo, enquanto que grandes volumes de magmas poderiam ser gerados por fusão incon- 
gruente. Entretanto, em zonas que já estão em altas temperaturas, quando há entrada ou circulação de volumes consideráveis de água, os processos de fusão são facilitados e podem ocorrer em larga escala (Sawyer et al., 2011).

Conforme Sawyer et al. (2011) rochas pelíticas produzem líquidos de composição granítica a partir de fusão incongruente a temperaturas da ordem de $720 \sim 820{ }^{\circ} \mathrm{C}$. Magmas de composições tonalíticas são obtidos por fusão incongruente a temperaturas da ordem de $750{ }^{\circ} \mathrm{C}$ em fontes como metagrauvacas e $800{ }^{\circ} \mathrm{C}$ de anfibolitos. Este processo de fusão incongruente por quebra de minerais hidratados explica de forma satisfatória fusões destas composições para estes tipos de rochas. Entretanto, não é adequado para rochas quartzo-feldspáticas que geralmente contém poucos minerais hidratados em sua composição, como leucogranitos, trondhjemitos e tonalitos.

Estudos recentes mostram que terrenos metamórficos podem fundir parcialmente quantidades significativas com a entrada de líquido no sistema, levando a fusão por water-fluxed melting a temperaturas em torno de $700{ }^{\circ} \mathrm{C}$. A origem do líquido nestes casos pode ser por reações de desidratação de metapelitos ou câmaras próximas, por infiltrações profundas de águas meteóricas, fluidos associados às zonas de cisalhamento, ou ainda, oriundos do manto (Sawyer et al., 2011).

Desta forma, granitos peraluminosos podem fornecer informações importantes a respeito do ambiente tectônico, bem como auxiliar no entendimento da evolução tectônica e termal de um cinturão orogênico.

No contexto geológico do Escudo Sul-riograndense, granitos peraluminosos são identificados principalmente na região de Encruzilhada do Sul, no domínio central do Cinturão Dom Feliciano. Estes granitos são descritos por diversos autores a partir de suas características de campo, petrográficas, mineralógicas, estruturais, químicas, bem como discutidos seus processos de gênese e fontes (Fernandes et al., 1995; Koester, 1995; Nardi \& Frantz, 1995; Philipp, 1998; Koester et al., 2001a, 2001b, 2002; Frantz et al., 2003; Philipp et al., 2013). Dentre este magmatismo, os principais corpos graníticos são os metagranitoides Arroio Francisquinho e Cordilheira, pertencentes a Suíte
Granítica Cordilheira, descritos por Koester et al. (2001a, 2001b). Estas rochas são datadas e interpretadas por estes autores, como um importante evento de magmatismo neoproterozoico sintectônico à Zona de Cisalhamento Transcorrente Dorsal de Canguçu, com idades de cristalização entre 630 a 617 Ma.

Trabalhos de mapeamentos geológicos no sudeste do Cinturão Dom Feliciano (UFRGS, 1972; Trainini, 1987; Philipp, 1998; Wildner et al., 2007, Klein, 2012) reportam a presença de um corpo granítico peraluminoso na região de Arroio Grande, denominado de Granito Figueirinha (UFRGS, 1972), Três Figueiras (Trainini, 1987; Philipp, 1998) e Arroio Grande (Wildner et al., 2007). A idade de cristalização magmática desse granitoide é de $558 \pm 57 \mathrm{Ma}$, obtida pelo método Th-U-Pb em cristais de monazita a partir de EPMA (Tickyj et al., 2004).

O objetivo deste trabalho é realizar a caracterização geológica, estrutural, geoquímica e geocronológica do Granito Três Figueiras (GTF), que representa um importante evento de magmatismo neoproterozoico peraluminoso associado à Zona de Cisalhamento Arroio Grande no sudeste do Cinturão Dom Feliciano.

\section{2 Área, materiais e métodos}

\subsection{Localização da área}

A área de estudo está localizada no Cinturão Dom Feliciano, cinturão orogênico neoproterozoico relacionado ao ciclo Brasiliano/Pan-Africano. Esse cinturão se estende de Punta del Este (Uruguai) até o leste do estado de Santa Catarina no Brasil (Heilbron et al., 2004).

No Rio Grande do Sul o Cinturão Dom Feliciano é dividido em três domínios, baseado em critérios geológicos e geofísicos (Fernandes et al., 1995): domínios Ocidental, Central e Oriental. 0 Domínio Oriental, onde está situado o GTF, é limitado a oeste pela Zona de Cisalhamento Dorsal de Canguçu e Sutura de Porto Alegre, que o separam do Domínio Central. A leste, é limitado pela Planície Costeira (sedimentos quaternários). A norte, por rochas metassedimentares paleozoicas e mesozoicas da Bacia do Paraná. A sul o domínio se es- 
tende até Punta del Este, no Uruguai.

No Domínio Oriental no Rio Grande do Sul, parcialmente equivalente ao Batólito Pelotas (Fragoso-César et al., 1986), predominam granitoides cálcio-alcalinos alto-K de idade neoproterozoica, vinculados à zona de subducção. Subordinadamente, são encontrados xenólitos métricos a quilométricos de rochas metamórficas diversas, que representam crosta continental e oceânica pretérita (Fragoso César et al., 1986; Philipp et al., 2002).

As unidades graníticas dos Domínios Oriental e Central foram agrupadas em seis suítes intrusivas (Philipp, 1998; Philipp et al., 2002), sendo elas: Pinheiro Machado, Erval, Encruzilhada do Sul, Viamão, Dom Feliciano e Cordilheira. Por sua composição, o GTF é incluído junto aos granitos da Suíte Granítica Cordilheira, de afinidade peraluminosa (Philipp et al., 2013).

O Domínio Oriental é marcado pela presença de zonas de cisalhamento que controlam o magmatismo pós-orogênico, denominadas por Bitencourt \& Nardi (2000) de Cinturão de Cisalhamento Sul Brasileiro, o qual compreende uma série de zonas de cisalhamento transcorrentes anastomosadas, com direção dominantemente N-S a N60 ${ }^{\circ}$, com cinemática tanto dextral quanto sinistral. Dentre essas zonas destaca-se a Zona de Cisalhamento Transcorrente Dorsal de Canguçu, que possui um importante evento de magmatismo peraluminoso sintectônico associado, de idade $630 \sim 617 \mathrm{Ma}$, relacionado às rochas da Suíte Granítica Cordilheira (Koester et al., 2001a, 2001b). Já na porção SE do Domínio Oriental, Machado et al. (1995) descrevem as Zonas de Cisalhamento Ayrosa Galvão, Zona de Cisalhamento Erval e Zona de Cisalhamento Arroio Grande, estando o GTF associado a essa última estrutura.

$\mathrm{Na}$ área de estudo (Fig. 2), além do GTF, são encontradas unidades neoproterozoicas relacionadas ao (i) Complexo Ofiolítico Arroio Grande; (ii) Complexo Pinheiro Machado; (iii) Granito Chasqueiro; e (iv) Granito Capão do Leão. Dessas, apenas o granito Capão do Leão não faz contato com o GTF. A porção leste do GTF é recoberta por sedimentos da Planície Costeira.

O Complexo Ofiolítico Arroio Grande (Ramos \& Koester, 2014, 2015) é composto por anfibolitos, serpentinitos e xistos magnesianos cromíferos (metaultramáficas), além de rochas metassedimentares químicas (mármores Matarazzo) e clásticas (xistos e quartzitos Arroio Grande), estas últimas sendo as rochas metamórficas mais abundantes na região. Estas rochas são interpretadas como fragmentos de crosta oceânica e sedimentos marinhos associados, anexados ao continente por processos de obducção e posteriormente metamorfizados.

O Complexo Pinheiro Machado na área de estudo é caracterizado por granitoides cinzentos equigranulares a porfiríticos, com origem relacionada à subducção de crosta oceânica sob margem continental espessada, com fragmentos de gnaisses e anfibolitos (Philipp et al., 2000; Loureiro, 2013; Ramos \& Koester, 2014).

0 Granito Chasqueiro é um granito de coloração cinza claro, porfirítico com megacristais de K-feldspato imersos em uma matriz equigranular média, encaixado na Zona de Cisalhamento Arroio Grande. Nas zonas afetadas pelo cisalhamento desenvolve texturas protomiloníticas a miloníticas. Apresenta contatos bruscos e intrusivos com a litologias encaixantes (Philipp, 1998; Vieira et al., 2016).

0 Granito Capão do Leão é um corpo em forma elíptica com estrutura maciça. São leucogranitos de textura equigranular média a grossa, composição sieno a monzogranítica, com granada como principal fase acessória (Silva \& Koester, 2014).

\subsection{Materiais e métodos}

Para este trabalho foram realizadas etapas de campo, as quais foram descritos 79 pontos. Foram realizados croquis, tomadas atitudes de estruturas planares e lineares, fotografias de feições de meso- e macroescala, bem como mapeada as dimensões do corpo granítico e suas relações de contato com outras litologias. 0 tratamento dos dados estruturais foi realizado utilizando o software Stereonet.

Foram selecionadas 15 amostras para confecção de lâminas delgadas junto ao Laboratório de Apoio Analítico e Preparação de Amostras do Centro de Estudos em Petrologia e Geoquímica. As descrições das lâminas foram 


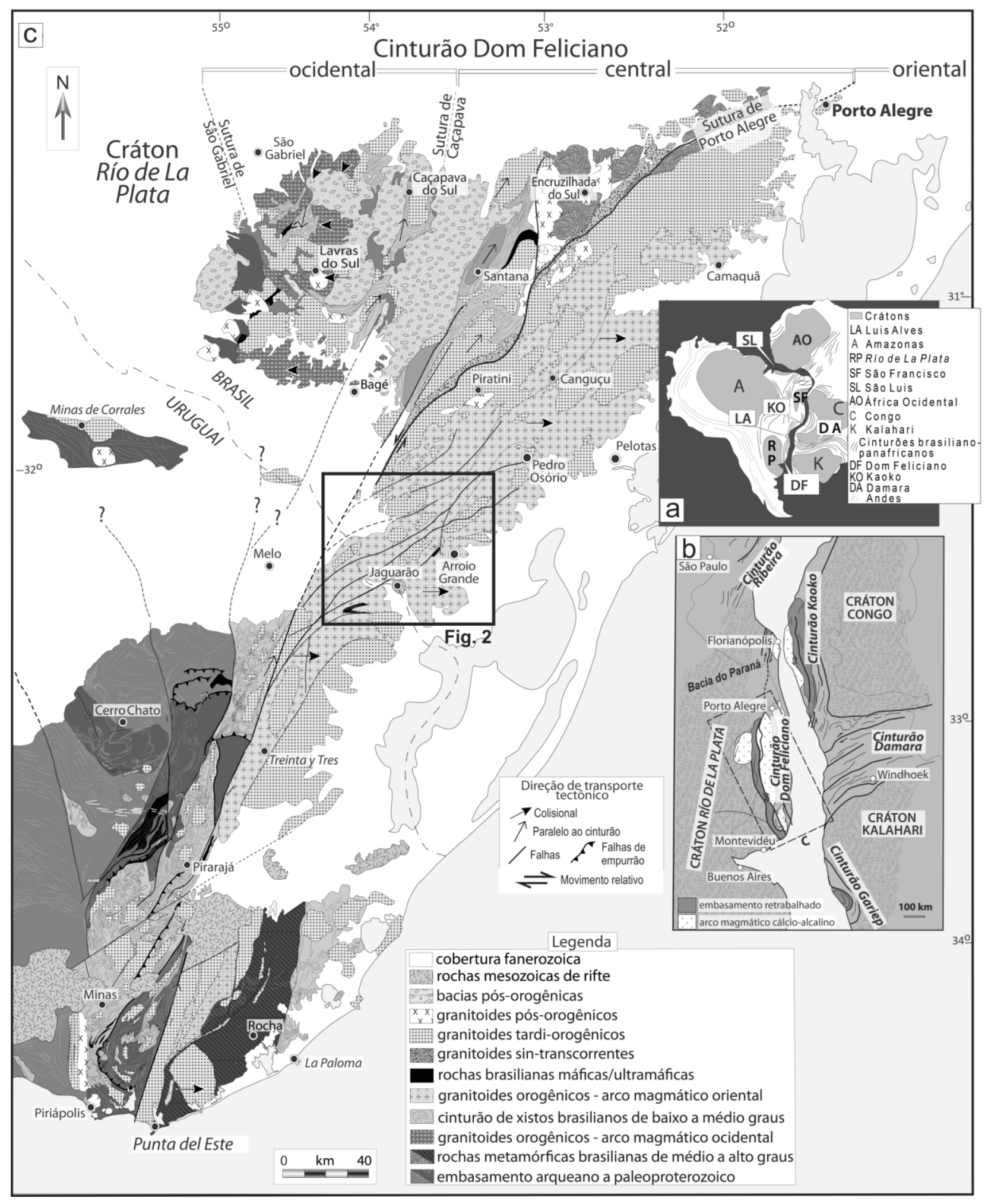

Figura 1. Esboço geológico do Cinturão Dom Feliciano no Escudo Uruguaio-sul-rio-grandense. A) Configuração do Gondwana com as principais áreas cratônicas e cinturões relacionados ao Cinturão Dom Feliciano; B) Mapa geológico do Cinturão Dom Feliciano e Cráton Rio de La Plata no sul do Brasil e Uruguai; C) Localização do Cinturão Dom Feliciano e cinturões africanos adjacentes na configuração do Gondwana (modificado de Masquelin et al., 2012).

Figure 1. Geological context of Dom Feliciano Belt in the Uruguayan-sul-rio-grandense Shield. A) Gondwana configuration with main cratonic areas and mountain belts related to Dom Feliciano Belt; B) Geologic map of Dom Feliciano Belt and Rio de La Plata Craton in south Brazil and Uruguay; C) Location of Dom Feliciano Belt and adjacent African Belts on Gondwana configuration (modified from Masquelin et al., 2012). 


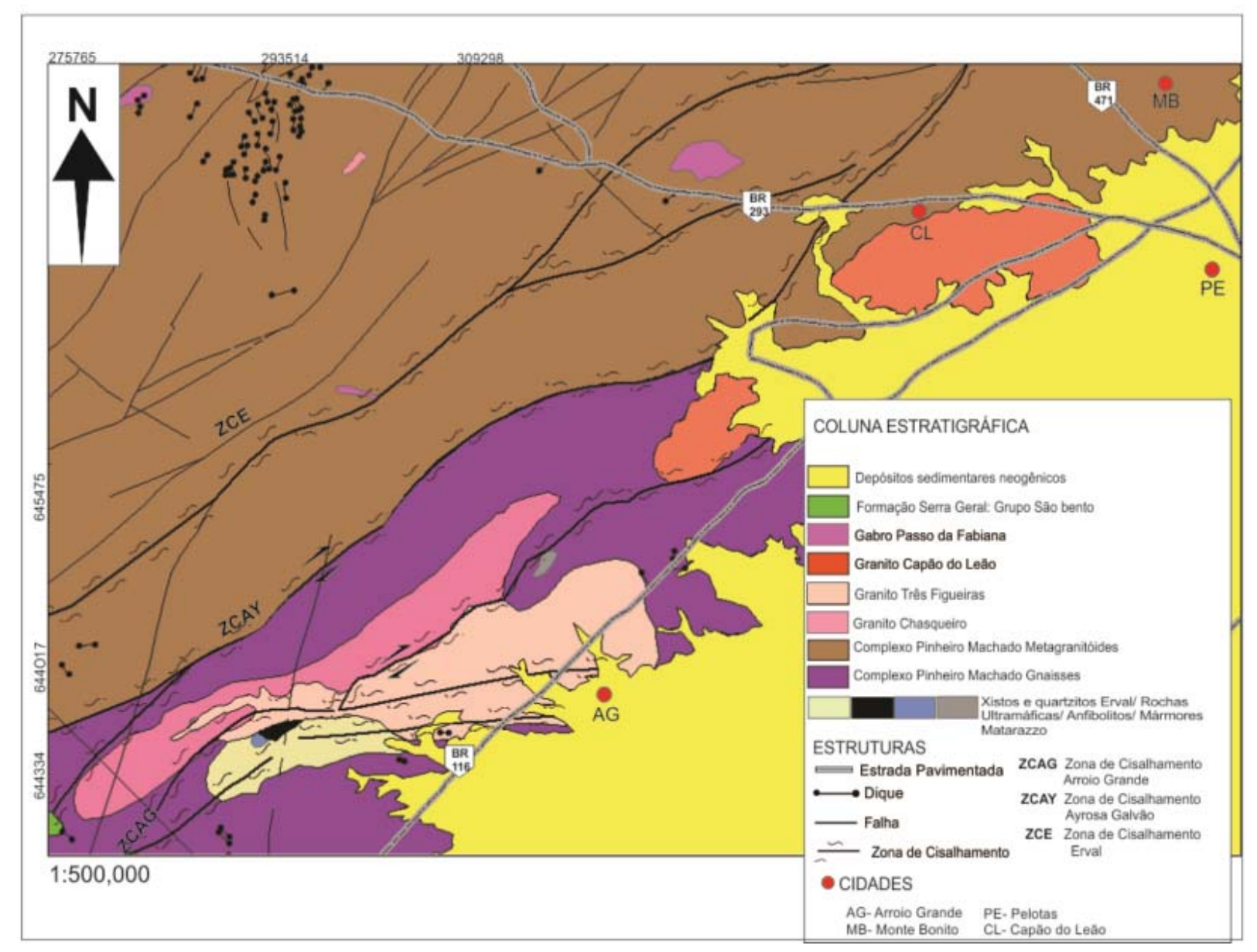

Figura 2. Mapa geológico da região de Arroio Grande, extremo sudeste do Cinturão Dom Feliciano (RS).

Figure 2. Geologic map of the Arroio Grande region, southeastern Dom Feliciano Belt (RS).

realizadas com auxílio de microscópio Meiji Techno® ML9720. Foram realizadas contagens modais em 5 amostras correspondentes à porção magmática indeformada, com cerca de 500 pontos por lâmina.

Foram selecionadas 15 amostras representativas do granito para análises químicas. As amostras selecionadas foram encaminhadas para preparação e análise no Acme Analitical Laboratorie Ltd., no Canadá, onde foram determinados elementos maiores, traços e terras raras, por meio de ICP-MS. 0 tratamento e geração dos gráficos geoquímicos foi realizado utilizando o software GCDkit (Janoušek et al., 2006).

As determinações das idades U-Pb SHRIMP foram conduzidas no Centro de Pesquisas Geocronológicas da Universidade de São Paulo, Brasil. Os cristais de zircão foram separados usando as convencionais técnicas de separação dos líquidos pesados e magnética. Posteriormente, foi preparado o mount com os cristais em resina epóxi e polidos para exposição do interior dos grãos, sendo utili- zado o padrão TEMORA-2 (Black et al., 2004). As amostras foram revestidas com ouro e os mounts polidos foram examinados de forma abrangente com microscópio eletrônico de varredura FEI Quanta 250 equipado com detectores de elétrons secundários e catodoluminescência no IGc-CPGeo -USP. As condições mais comuns de análise foram: emissão de corrente de $60 \mu \mathrm{A}$, voltagem de aceleração de $15,0 \mathrm{kV}$, diâmetro de irradiação de $7 \mu \mathrm{m}$, tempo de aquisição de $200 \mu$ s e resolução de 1024 x 884. Posteriormente, foi realizada a análise U-Pb dos mounts, utilizando um equipamento SHRIMP -IIe conforme os procedimentos analíticos descritos por Williams (1998). A correção do $\mathrm{Pb}$ comum foi feita com base no ${ }^{204} \mathrm{~Pb}$ medido, e a razão típica de erro ${ }^{206} \mathrm{~Pb} /{ }^{238} \mathrm{U}$ foi menor que $2 \%$. A abundância de urânio e razão U-Pb foram calibrados pelo padrão TEMORA e as idades calculadas por meio do software Isoplot versão 3.0 (Ludwig, 2003). Os erros são referidos como desvios de $1 \sigma$ e as idades foram calculadas com intervalo de confiança de $95 \%$. 


\section{Resultados}

\subsection{Geologia}

Trabalhos anteriores (UFRGS, 1972; Philipp, 1998) descrevem a geologia estrutural da região de Arroio Grande, destacando a importância e controle de falhamentos (para o posicionamento de plútons) com disposições NE-SW, sendo que o principal é um sistema de deformação dúctil de alto ângulo, com direção $\mathrm{N} 70^{\circ} \mathrm{E}$, denominado Zona de Cisalhamento Arroio Grande, à qual o GTF está associado espacialmente.

A tectônica da região tem um controle estrutural WSW-ENE, que se manifesta em todas as escalas de observação. UFRGS (1972) descreve o GTF como um corpo granítico alongado, com estrutura foliada, que aflora em uma crista com orientação E-W, com largura de 0,5 a 1 km e uma extensão de $14 \mathrm{~km}$. No terreno, essas cristas são destacadas na paisagem e configuram quebras de relevo na região (Fig. 3).

O GTF é um granito com duas micas que constitui em planta um corpo com formato alongado segundo uma direção E-W, com aproximadamente $32 \mathrm{~km}$ de extensão variando de $6 \mathrm{~km}$ de espessura na porção oeste até $12 \mathrm{~km}$ de espessura na porção leste. Aflora na forma de matacões e lajeados com dimensões variadas. Sob o ponto de vista textural e estrutural, possui duas porções com características distintas, sendo i) porção magmática indeformada e ii) porção deformada com texturas e estruturas tectônicas de caráter dominantemente dúctil. São granitos strictu sensu, de coloração alaranjada variando em tons de cinza nos termos miloníticos.

Este granito possui textura equigranular média, localmente heterogranular com cristais mais desenvolvidos de muscovita formando palhetas de até $1,5 \mathrm{~cm}$. Sua mineralogia essencial é composta por K-feldspato, plagioclásio, quartzo, muscovita e/ou biotita. A presença de minerais acessórios como granada e turmalina é comum, tendendo a ocorrer em concentrados. Os termos indeformados possuem estrutura maciça, sendo possível observar localmente uma foliação incipiente marcada pelo alinhamento das micas. A foliação milonítica é bem desenvolvida nos termos deformados, marca- da por trilhas de micas e/ou agregados alongados de quartzo, formando protomilonitos e milonitos.

Embora raras, há ocorrências localizadas de xenólitos anfibolíticos centimétricos (Fig. 4). Injeções pegmatíticas centimétricas a decimétricas concordantes e discordantes aos planos de foliação são comuns. Localmente foram encontradas injeções tardias de granulação muito fina que intrudem paralelas à foliação (Fig. 4).

\subsection{Geologia Estrutural}

O GTF tem seu posicionamento controlado e afetado pela Zona de Cisalhamento Arroio Grande, a qual lhe confere uma grande variedade de texturas e estruturas e uma foliação de origem tectônica que são dominantes. As zonas de deformação dúctil formam protomilonitos, localmente milonitos, com textura porfiroclástica marcada por porfiroclastos de K-feldspato e plagioclásio de até $1 \mathrm{~cm}$ e cristais de muscovita (mica-fish). A foliação é marcada por textura lepidoblástica em cristais de muscovita e biotita ou por agregados estirados de quartzo.

A trama milonítica desenvolvida é marcada por uma foliação tectônica subvertical de cisalhamento (foliação $\mathrm{C}$ ) com ângulo de mergulho $>70^{\circ}$ dominantemente para SE e subordinadamente para NW marcada pelo alinhamento preferencial das micas e agregados estirados de quartzo e feldspato, com direção WSW-ENE. Pode-se observar uma leve concentração de pontos tendendo para $\mathrm{NE}$, que correspondem a medidas coletadas no extremo oeste do corpo, onde este inflete levemente para SW. Em diagrama de contagem de polos, a foliação apresenta um valor médio de $081 \mathrm{com}$ mergulho de $83^{\circ}$ para SE. Associado a essa foliação, apresenta uma lineação de estiramento do quartzo, com caimento sub-horizontal, ora para NE, ora para SW. No diagrama de contagem, é possível observar três tendências distintas, sendo a predominante com sentido 083 e caimento de $10^{\circ}$ para ENE, e duas subordinadas, uma com sentido de 045 e caimento de $10^{\circ}$, e outra com sentido 263 e caimento de $14^{\circ}$ (Fig. 5).

Localmente apresenta o desenvolvimento de uma foliação S-C, com a progressão da deformação, especialmente na porção oeste do corpo onde este 


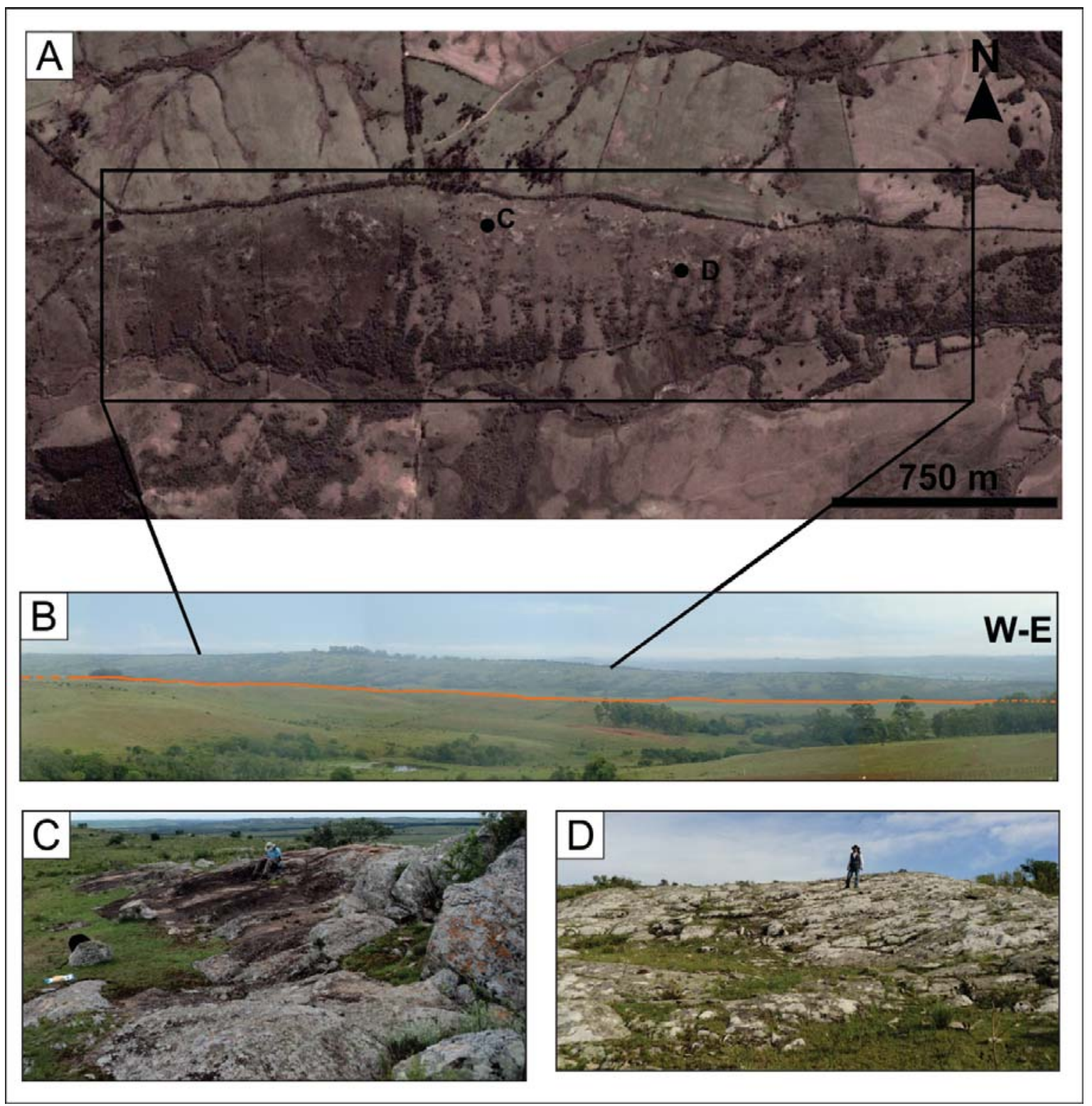

Figura 3. Afloramentos típicos do granito estudado. A) Imagem de satélite (Google Earth®) das cristas formadas pelo Granito Três Figueiras; B) Cristas alongadas com orientação W-E, que configuram quebras de relevo e se destacam na paisagem da região; C) Afloramento em lajeado alongado W-E; D) Cristas alongadas W-E.

Figure 3. Typical outcrops of the studied granite. A) Satellite image (Google Earth ${ }^{\circledR}$ ) of the Três Figueiras Granite crest; B) W-E oriented, elongated crest, which marks a relief contrast; C) W-E elongated outcrop; D) W-E elongated crest.

inflete para NE-SW. A foliação de cisalhamento C é formada pela orientação dos cristais de micas, seja por reorientação ou por recristalização formando finas trilhas enquanto a $S$ é marcada pela inflexão dos cristais de mica-fish, cristais de K-feldspato e plagioclásio.

A cinemática da zona de cisalhamento é evidenciada neste granito por indicadores de macro e micro-escala como pares $\mathrm{S}$-C, assimetria de porfiroclastos de feldspato e mica-fish. As injeções pegmatíticas tendem a registrar a cinemática, preservando cristais de feldspato com caudas assimétricas dextrais (Fig. 6).

\subsection{Petrografia}

O GTF é constituído por sieno a monzogranitos (Fig. 7). Possui cor alaranjada a cinza. A mineralogia principal é composta por K-feldspato (35-50 \%), quartzo (19-30\%), plagioclásio (23-28 $\%$ ) e muscovita + biotita (7-10 \%), sendo que nos termos menos evoluídos a biotita é predominante (6 8\%), enquanto a muscovita predomina nos mais evoluídos (5 8 \%). Os minerais acessórios são granada, turmalina, zircão, monazita e apatita. De modo geral, possui textura equigranular média, localmente inequigranular com cristais mais 
desenvolvidos de muscovita, quartzo ou feldspato imersos em uma matriz fina. Possui dominantemente estrutura maciça, embora localmente apresente uma leve tendência a uma foliação magmática marcada pelo alinhamento incipiente das micas.

Ao microscópio, nos termos indeformados (Fig. 8), K-feldspato e quartzo são os constituintes principais, ocorrendo como cristais anédricos com contatos curvilíneos, que imprimem uma textura alotriomórfica nestes granitos.

O K-feldspato ocorre dominantemente sem macla, por vezes com macla xadrez ou carlsbad desenvolvidas principalmente nas bordas dos grãos. 0 tamanho dos cristais varia de 0,5 a $3 \mathrm{~mm}$, sendo predominantes os cristais com tamanho entre 0,7 a $2 \mathrm{~mm}$. 0 quartzo possui extinção ondulante

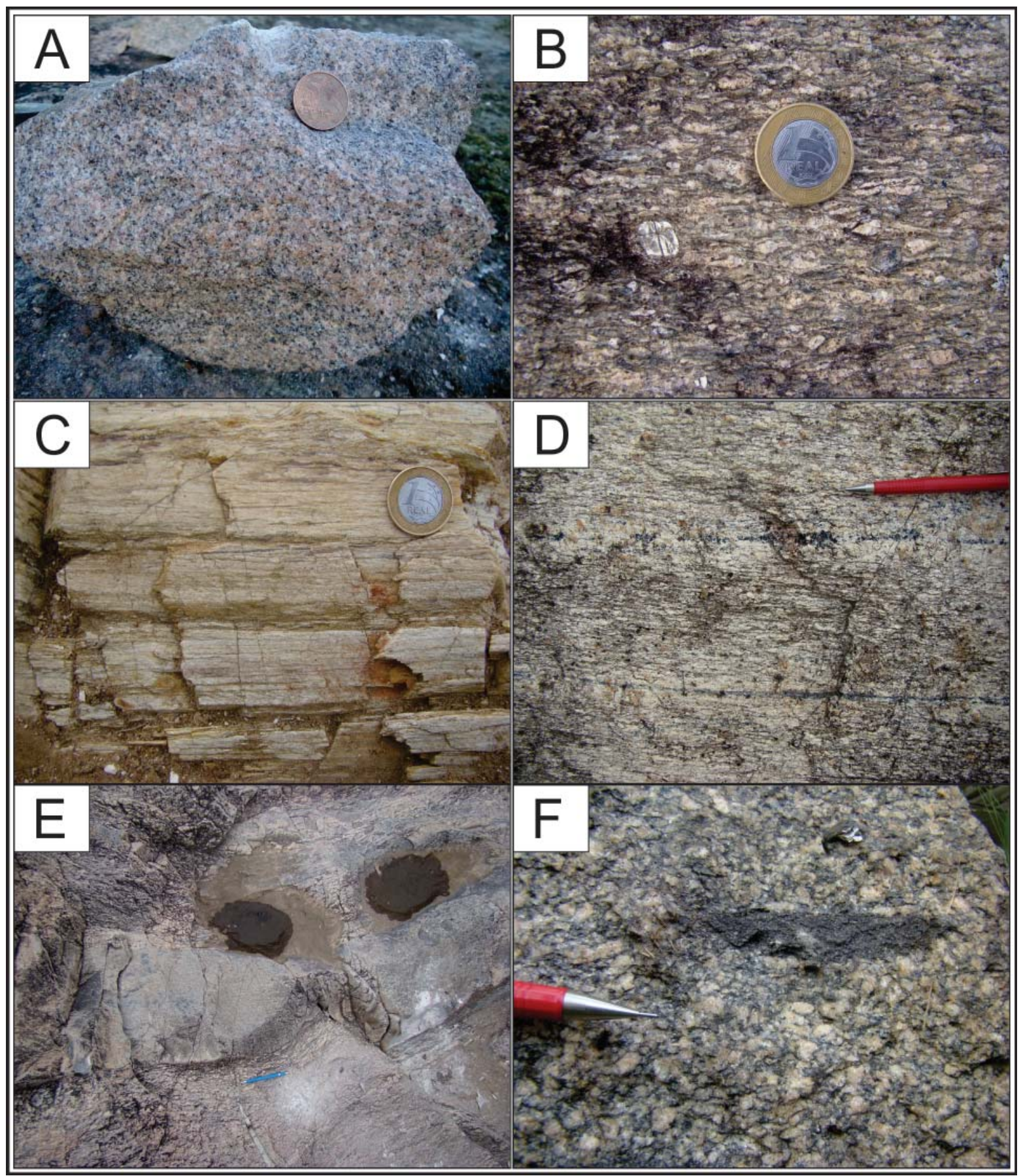

Figura 4. Feições de campo do Granito Três Figueiras. A) Granito indeformado; B) Protomilonito com porfiroclasto de muscovita; C) Textura milonítica; D) Níveis concentrados de turmalina (em preto); E) Intrusão tardia de textura fina; F) Xenólito centimétrico de composição anfibolítica.

Figure 4. Field characteristics of the Três Figueiras Granite. A) Undeformed granite; B) protomylonitic texture with muscovite porphyroclast; C) Mylonitic texture; D) Tourmaline concentrations (black layers); E) Late-intrusions with fine equigranular texture; F) Centimeter-sized xenolith with amphibolitic composition. 


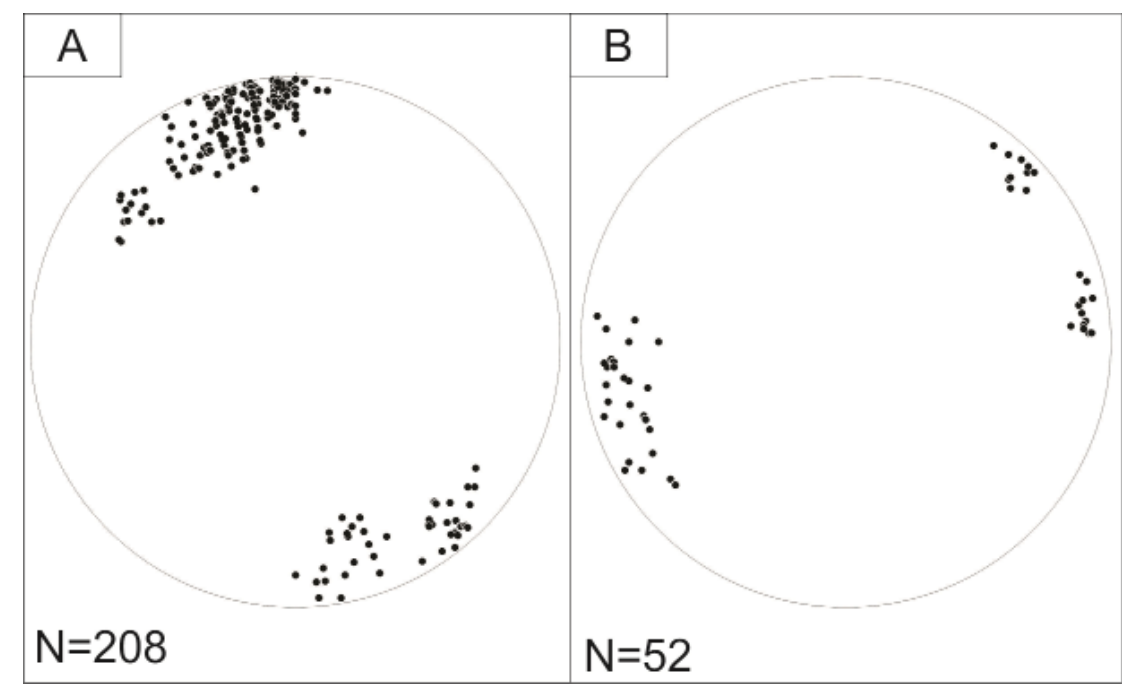

Figura 5. Estereogramas da foliação e lineação do Granito Três Figueiras mostrando a direção principal W-E e o mergulho preferencial para SE. A) Polos das foliações; B) Estereograma com as lineações de estiramento do quartzo.

Figure 5. Foliation and lineation stereograms of Três Figueiras Granite showing a W-E preferred orientation with dip to SE. A) Foliation poles; B) Quartz stretching lineation stereograms.
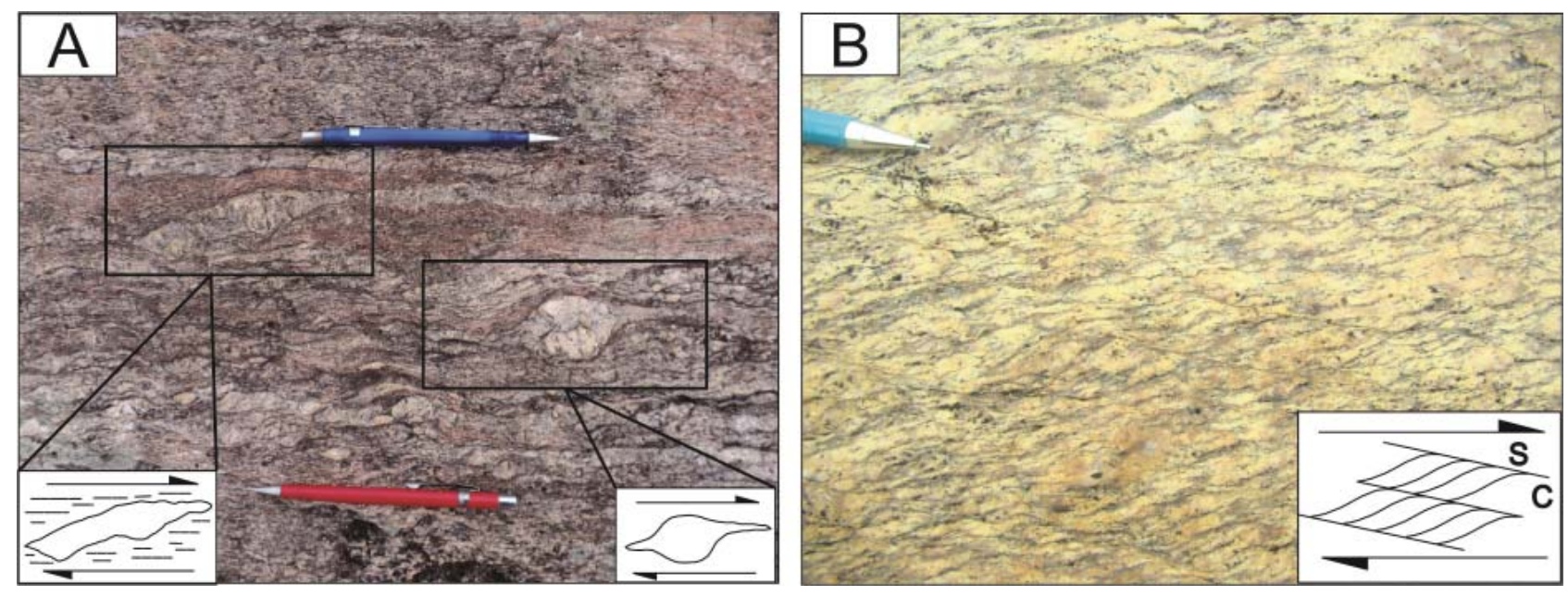

Figura 6. Indicadores cinemáticos do Granito Três Figueiras. A) Porfiroclastos com caudas assimétricas dextrais; B) Pares S-C dextrais.

Figure 6. Kinematic indicators of Três Figueiras Granite. A) Porphyroclasts with dextral asymmetric tails; B) Dextral S-C pairs.

e tende a formar agregados de cristais com formas irregulares e alongados, de tamanho entre 0,3 a 3,2 mm. 0 plagioclásio é anédrico a subédrico (até 2 faces retas), e possui macla polissintética pouco desenvolvida, nem sempre visível, por vezes levemente deformada em forma de cunha. 0 tamanho dos cristais varia de 0,3 a $3 \mathrm{~mm}$ sendo mais comuns os cristais menores com 0,4 a $0,8 \mathrm{~mm}$. Localmente são encontrados mirmequitos, nas bordas dos cristais de plagioclásio quando em contato com o K-feldspato, e mais raramente em contato com o quartzo. A muscovita ocorre como palhetas, os cristais são subédricos com pelo menos duas faces retas. De modo geral os cristais variam entre $0,2 \mathrm{a}$
$0,8 \mathrm{~mm}$, embora ocorram cristais mais desenvolvidos de 3 a $4 \mathrm{~mm}$. Inclusões de muscovita aciculares nos cristais de feldspato são comuns. A biotita é o mineral essencial menos abundante, ocorrendo como cristais pequenos, entre 0,1 até $0,7 \mathrm{~mm}$ com pleocroísmo variando em tons de marrom amarelado até castanho escuro. Não raro, ocorre em intercrescimento com cristais de muscovita, se desenvolvendo sobre os planos de clivagem ou nas bordas das mesmas.

Nos termos deformados (Fig. 9), apresenta texturas e estruturas oriundas da milonitização. Desenvolve uma foliação tectônica de natureza milonítica, marcada pela reorientação dos cris- 
tais das micas e agregados estirados de quartzo. Alguns autores (e.g. Bitencourt \& Nardi, 1986; Paschier \& Trouw, 1996) apontam que as rochas graníticas reagem à deformação de forma heterogênea, de modo que o comportamento dúctil e a intensidade da deformação não se distribuem de forma uniforme pelo corpo rochoso, bem como a diferença de reologia dos minerais faz com que diferentes estruturas se desenvolvam, de acordo com a resistência dos mesmos à deformação. No GTF, é registrada essa diferença na distribuição da deformação em termos mais ou menos afetados, desde feições incipientes até o desenvolvimento de milonitos propriamente ditos.

Os efeitos visíveis macroscopicamente são a reorientação das micas e o desenvolvimento de uma estrutura protomilonítica a milonítica, conferindo à rocha uma textura porfiroclástica marcada por porfiroclastos de feldspatos e muscovita (fish) imersos em uma matriz quartzo-feldspática.

Os primeiros estágios da deformação são evidenciados nos termos com deformação incipiente, em que se observa que as micas tendem a assumir uma orientação preferencial, o quartzo tende a formar agregados e subgrãos e ocorre localmente recristalizado enquanto os feldspatos apresentam extinção ondulante e deformação das maclas (kinks).

Nos termos proto- e miloníticos, o quartzo adquire forte extinção ondulante e tende a formar agregados, frequentemente recristalizados, com formação de subgrãos na maioria dos cristais. Com incremento da deformação as feições de recristalização por bulging e subgrain rotation são muito comuns, constituindo a principal fase da matriz, ou localmente deformado em forma de fita, contornado cristais de feldspato. Os agregados recristalizados conferem à rocha uma textura inequigranular a seriada com arranjo interlobado, localmente poligonal, de tamanho variando entre 10 a $80 \mu \mathrm{m}$.

As micas tendem a formar uma foliação irregular e descontínua, por vezes anastomosada, e com incremento da deformação desenvolvem uma forte foliação tectônica marcada por trilhas finas ou com bandas quartzo-feldspáticas mais espessas. Os porfiroclastos de muscovita ocorrem

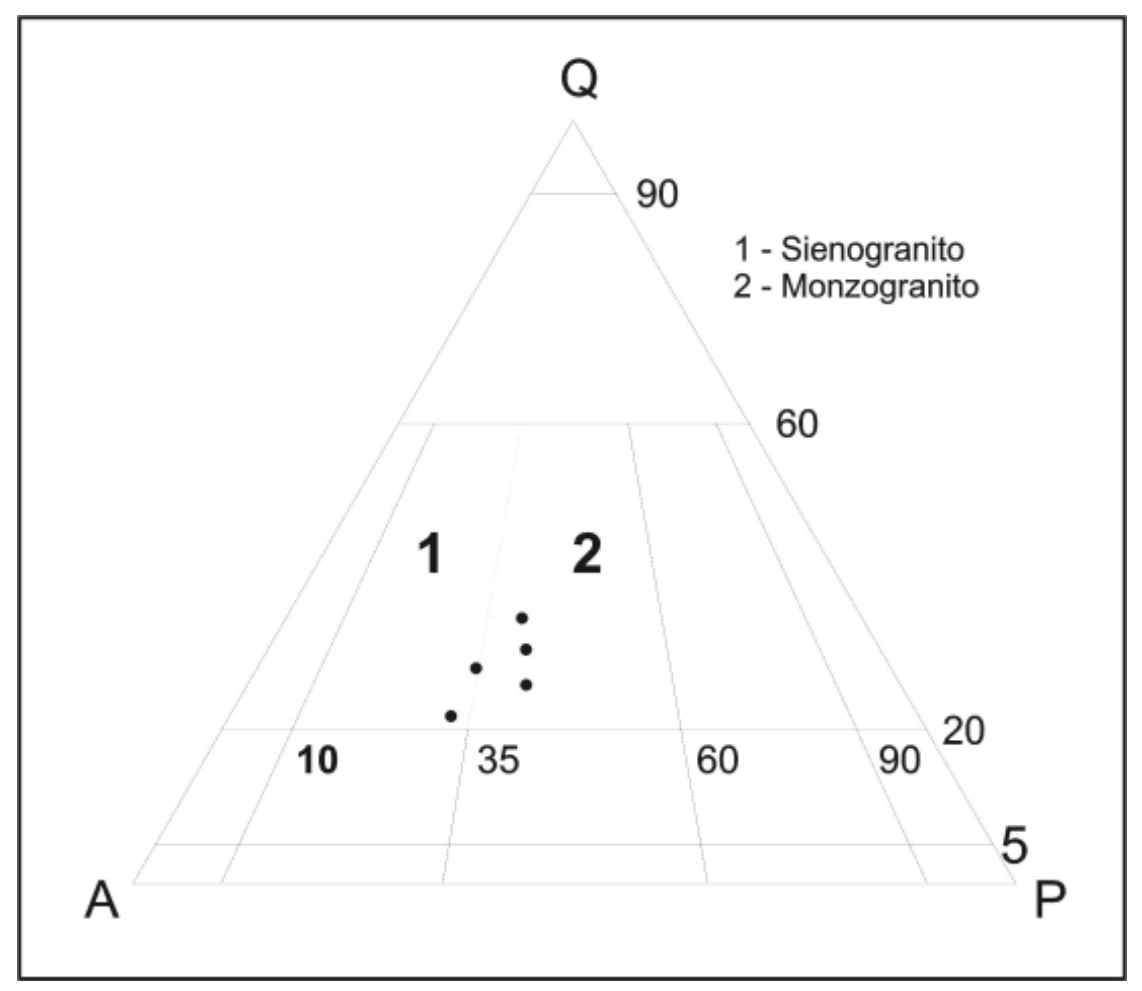

Figura 7. Composições modais das amostras indeformadas do Granito Três Figueiras dispostas no diagrama QAP (modificado de Streckeisen,1976).

Figure 7. Modal composition of the undeformed Três Figueiras Granite samples, ploted on QAP diagram (modified from Streckeisen, 1976). 

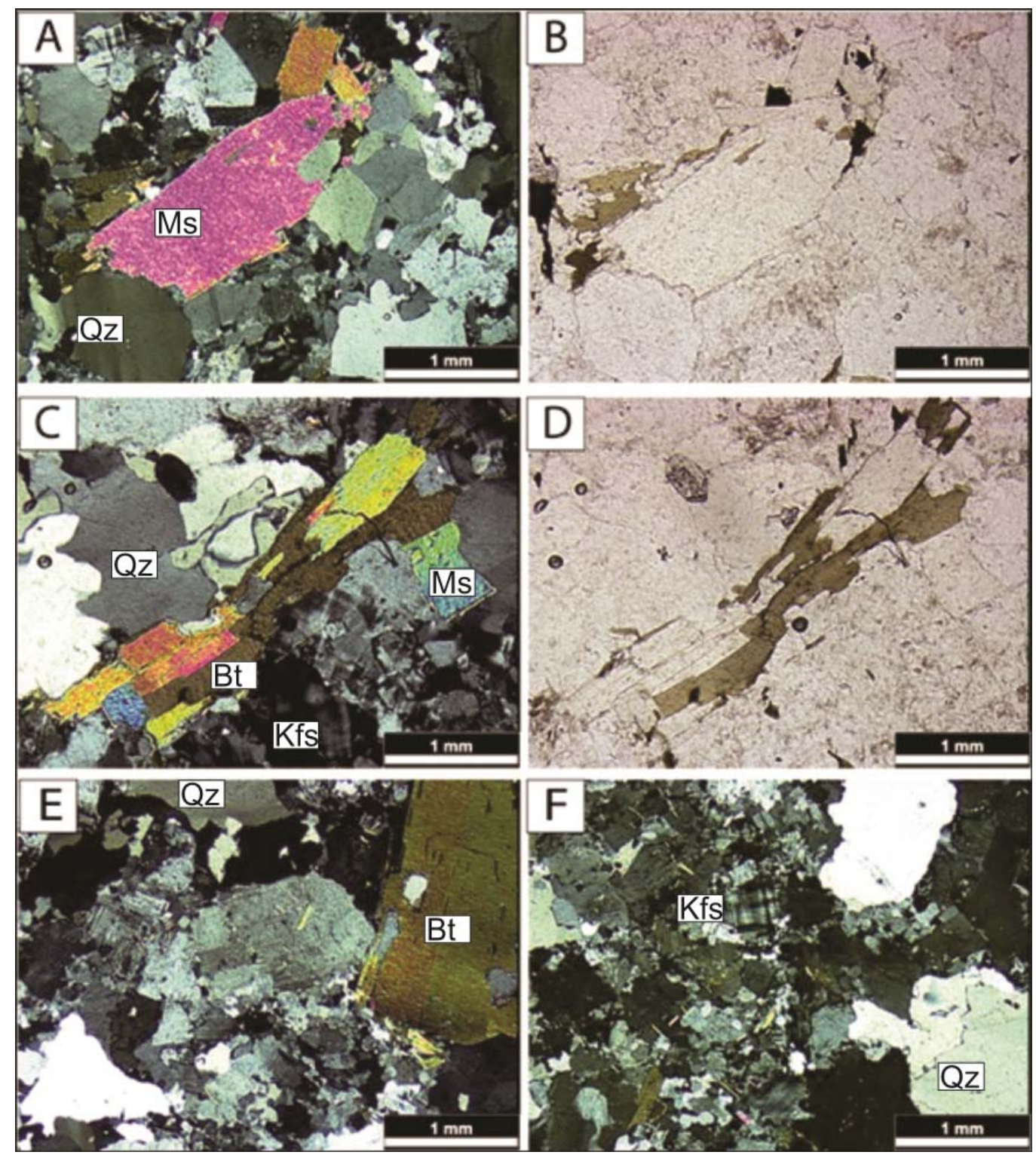

Figura 8. Aspectos microscópicos dos estágios não deformados do Granito Três Figueiras. A) Cristal de muscovita, nicóis cruzados (NC); B) Cristal de muscovita, luz polarizada (LP); C) Cristais de muscovita e biotita, NC; D) Cristais de muscovita e biotita, LP; E) Textura inequigranular alotriomórfica em quartzo e feldspatos, NC; F) Detalhe da textura alotriomórfica e cristais de Kfeldspato com dupla macla. Abreviações: $\mathrm{Bt}=$ biotita; Kfs = K-feldspato; Ms = muscovita; Qz = quartzo.

Figure 8. Microscopic aspects of undeformed stage of Três Figueiras Granite. A) Muscovite crystal, crossed polars (CP). B) Muscovite crystal, plane-polarized light (PPL). C) Biotite and muscovite crystals, CP. D) Biotite and muscovite crystals, PPL. E) Inequigranular allotriomorphic texture in quartz and feldspar, CP. F) Detail of allotriomorphic texture and twinned K-feldspars. Abbreviations: Bt = biotite; $K f s=K$-feldspar; $M s$ = muscovite; $Q z=$ quartz.

dobrados ou em forma fish e variam de tamanho entre 0,3 a $4,2 \mathrm{~mm}$.

Os K-feldspatos e plagioclásios tendem a formar porfiroclastos, manteados pelas trilhas de micas ou por agregados estirados de quartzos. Eventualmente ocorre a formação de subgrãos e até recristalização nas bordas dos cristais mais deformados em textura granoblástica poligonal com tamanho em torno de $50 \mu \mathrm{m}$. Alguns cristais apresentam apenas um núcleo e a borda totalmente recristalizada (mantled porfiroclast). Os cristais de plagioclásio podem apresentar deformação tec- tônica das maclas formando kinks. 0 tamanho dos porfiroclastos varia entre 0,7 a $3,8 \mathrm{~mm}$ sendo predominantes os cristais entre 1 a $2 \mathrm{~mm}$.

Os porfiroclastos de muscovitas-fish e feldspatos por vezes marcam um sentido dextral para deformação, formando texturas $\mathrm{S}-\mathrm{C}$, caudas assimétricas ou cristais mais desenvolvidos orientados em ângulo com a direção da foliação C (Fig. 10).

0 conjunto de estruturas e texturas observadas no GTF demonstra que seu posicionamento é controlado e afetado pela Zona de Cisalhamento 

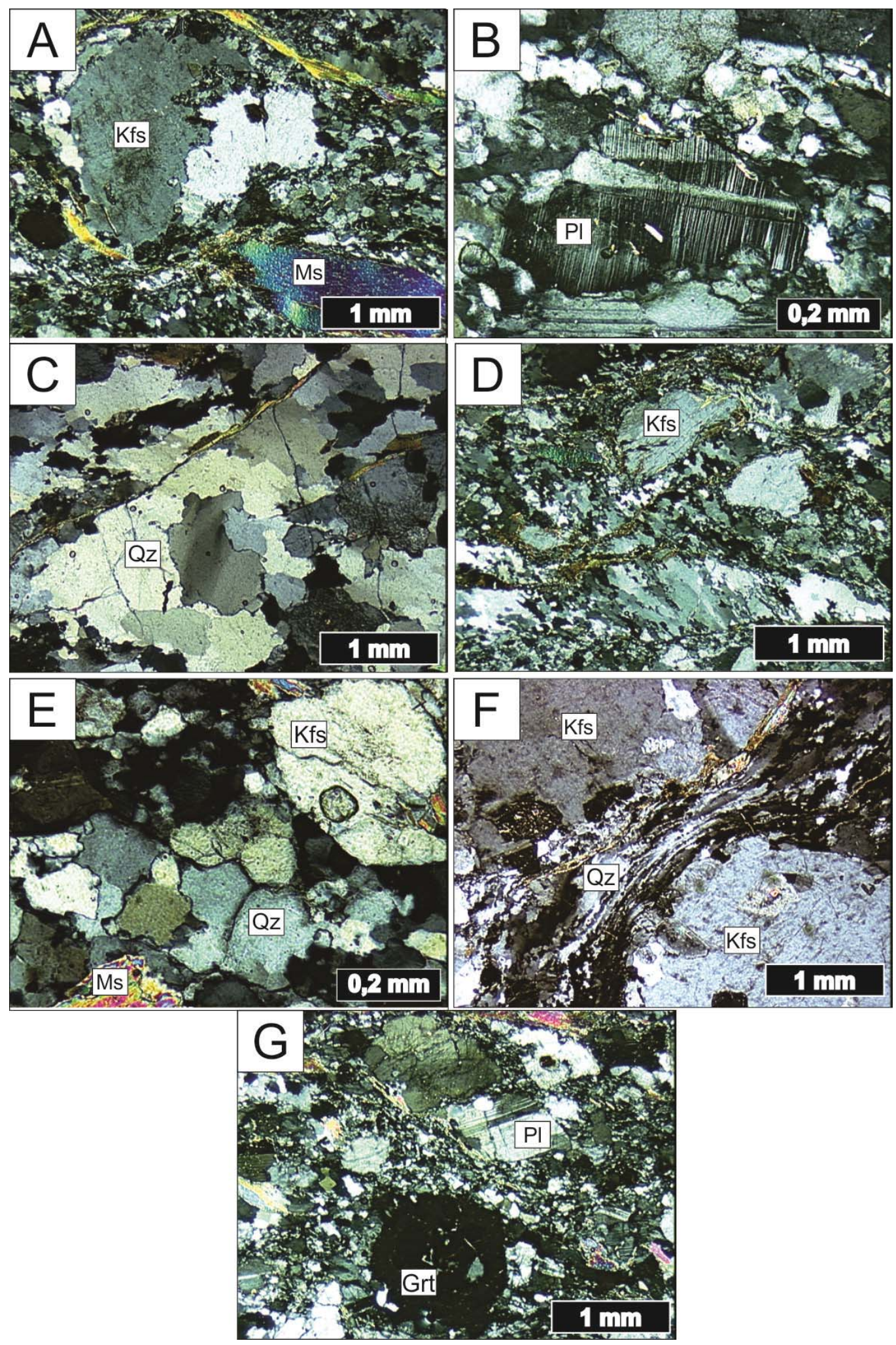

Figura 9. Aspectos microscópicos (em nicóis cruzados) dos estágios deformados do Granito Três Figueiras. A) Porfiroclasto de feldspato no centro, foliação marcada por muscovita fish e trilhas recristalizadas; B) Porfiroclasto de plagioclásio com deformação dos planos de macla; C) Formação de subgrãos e início da recristalização do quartzo; D) Matriz com textura fina recristalizada; E) Detalhe na recristalização da matriz com textura granoblástica poligonal em quartzo e feldspato; F) quartzo fitado circundando cristais de feldspato; G) Porfiroclasto de granada. Abreviações: Bt = biotita; Kfs = K-feldspato; Ms = muscovita; Pl = plagioclásio; $\mathrm{Qz}=$ quartzo.

Figure 9. Microscopic aspects (in crossed polars) of deformed stages of Três Figueiras Granite. A) Feldspar porphyroclast at the center, foliation marked by muscovite fish and recrystallized trails; B) Plagioclase porphyroclast with deformed twinning plans; C) Subgrain formation and beginning of quartz recrystallization; D) Thin recrystallized matrix; E) Detail on matrix recrystallization with polygonal granoblastic texture over quartz and feldspar grains; F) Ribbon quartz around feldspar Crystal; G) Garnet porphyroclast. Abbreviations: $B t=$ biotite; $K f s=K$-feldspar; $M s=$ muscovite; $P l=$ plagioclase; $Q z=$ quartz. 
Arroio Grande. Considerando que as rochas respondem à deformação de forma heterogênea, o comportamento dúctil e a intensidade da deformação não são distribuídos uniformemente pela extensão do corpo rochoso. Estas diferenças estão registradas em escala mineral, de modo que a diferença de reologia entre os cristais de quartzo e feldspato fazem com que cada fase responda de forma diferente à deformação (Passchier \& Trouw, 2005). No GTF é possível observar essa diferença de comportamento tanto em escala de afloramento quanto lâmina delgada, sendo possível identificar desde porções indeformadas (Fig. 8), com texturas e estruturas magmáticas preservadas, até a formação de protomilonitos (Fig. 9), subordinadamente milonitos.

Com base em Passchier \& Trouw (2005) (Fig. 11A), é possível estabelecer para o GTF um grau médio e temperaturas de recristalização e de- formação da ordem de 400 a $600^{\circ} \mathrm{C}$. Quando analisadas as feições microscópicas, a temperatura de recristalização e o grau de deformação podem ser inferidos a partir das texturas e reações observadas nos cristais, principalmente nos porfiroclastos de feldspato e no arranjo da matriz. 0 arranjo da matriz chega à textura granoblástica poligonal que, associada à recristalização parcial dos feldspatos, inclusive o plagioclásio, e a formação de mirmequitos por deformação, sugerem que esta se deu sob fácies anfibolito inferior a médio com temperaturas mínimas da ordem de $550^{\circ} \mathrm{C}$.

Ainda, as feições de sobreposição entre estruturas rúpteis sobre dúcteis, bem como o fraturamento de cristais de feldspato com preenchimento de material da matriz (Fig. 11B) mostra que a progressão da deformação acompanha o resfriamento do magma.
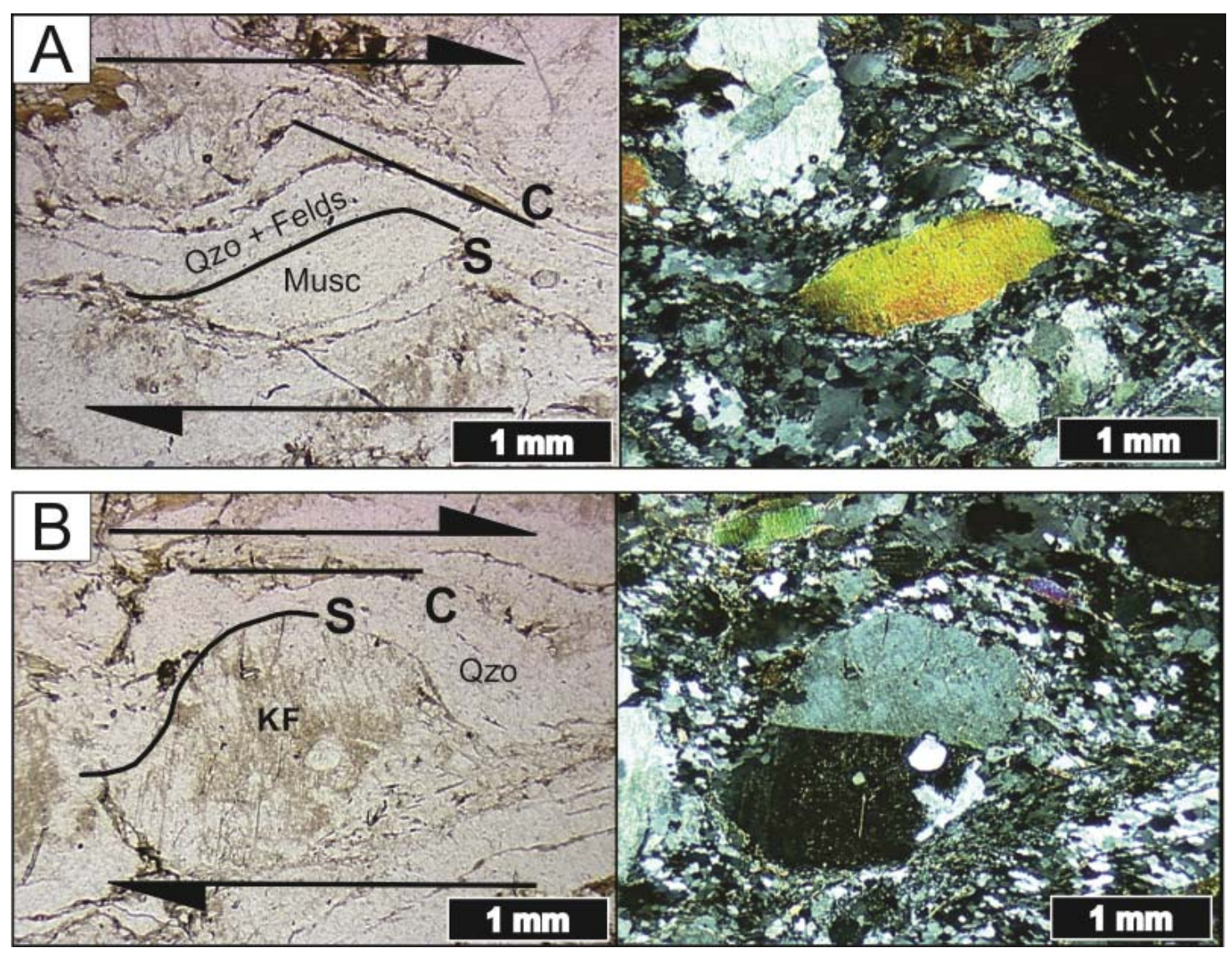

Figura 10. Indicadores cinemáticos ao microscópio. A) Cristal de muscovita-fish definindo uma foliação S-C; B) Porfiroclasto de K-feldspato com cauda assimétrica e definindo uma foliação S-C. Abreviação: Felds e KF = K-feldspato; Musc = muscovita; Qzo = quartzo.

Figure 10. Kinematic indicators on the microscope. A) Muscovite-fish crystals showing S-C foliation; B) K-feldspar porphyroclast with assimetric tail marking a $S$-C foliation. Abbreviation: Felds and KF=K-feldspar; Musc = muscovite; Qzo = quartz. 

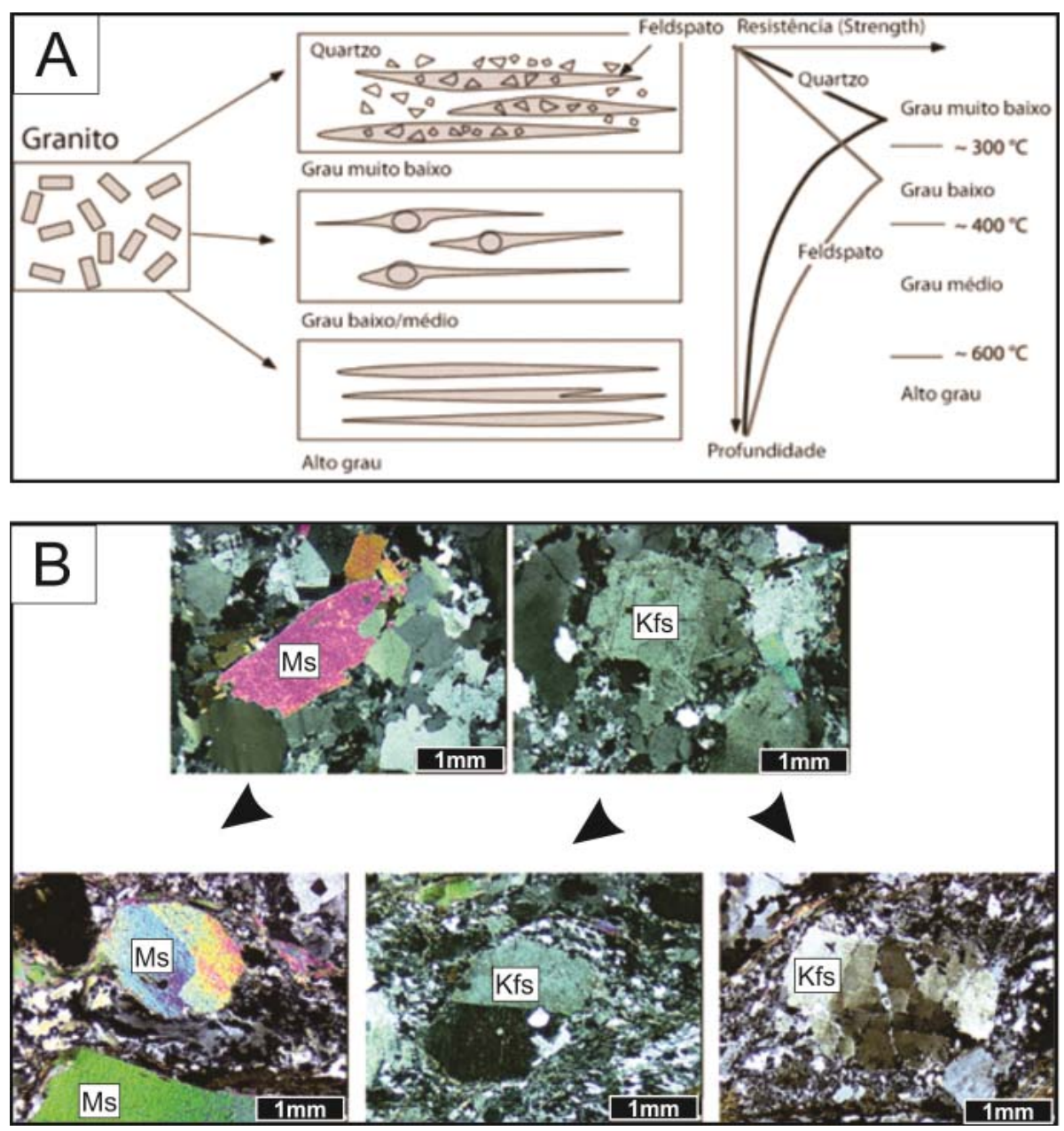

Figura 11. Comparativo entre texturas do Granito Três Figueiras. A) Mudanças de comportamento na deformação de agregados de quartzo e feldspato em função da profundidade e temperatura. Linhas retas representam comportamento rúptil, linhas curvas, comportamento dúctil. Em graus muito baixos, ambos possuem comportamento rúptil. Em grau baixo a médio, o quartzo começa a deformar ductilmente e o feldspato começa a formar porfiroclastos com bordas recristalizadas. Em alto grau o quartzo e o feldspato apresentam comportamento semelhante e deformam ductilmente (Modificado de Passchier \& Trouw, 2005); B) Muscovita e feldspato formando porfiroclastos e quartzo formando agregados estirados e recristalizando para grãos mais finos. Fotomicrografias em nicóis cruzados. Abreviações: Kfs = K-feldspato; Ms = muscovita.

Figure 11. Comparative Três Figueiras Granite textures. A) Changes in deformation behavior of quartz and feldspar, as a function of temperature and depth. Straight lines represent brittle behavior. Curved lines represent ductile behavior. Both minerals show brittle behavior at very low-grade conditions. At low- to medium-grade conditions, quartz starts to show ductile deformation, while feldspar grains tend to form porphyroclast with recrystallized edges. At high-grade, both quartz and feldspar show similar behavior with ductile deformation (Modified from Passchier \& Trouw, 2005); B) Muscovite and feldspar forming porphyroclast, while quartz grains form stretched aggregates and recrystallize. Crossed polar photomicrographs. Abbreviations: Kfs = K-feldspar; Ms = muscovite.

\subsection{Geoquímica}

O GTF é um granito de caráter peraluminoso a duas micas com índices de $\mathrm{A} / \mathrm{CNK}$ variando entre 1,07 e 1,21. A norma CIPW deste granito mostra que a soma dos componentes quartzo, ortoclásio e albita compreendem entre 80 e $90 \%$ da rocha, com coríndon normativo entre 1,2 a $3 \%$, o que corrobora a natureza peraluminosa deste granito. Possui alto teor de $\mathrm{SiO} 2$ entre 69,87 a $74,72 \%$, teores de $\mathrm{Al}_{2} \mathrm{O}_{3}$ entre 13,44 e $15,13 \%$, e teores elevados de álcalis $\left(\mathrm{K}_{2} \mathrm{O}+\mathrm{NaO}\right)$ entre 7,32 e 9,55 $\%$. Apresenta baixos teores de $\mathrm{FeO}+\mathrm{TiO}_{2}+\mathrm{MgO}$ com valores entre 1,13 e 3,78 \%. Com relação à classificação, as amostras plotam no campo dos granitos subalcalinos segundo o diagrama TAS (Cox et al., 1979). No diagrama de discriminação de granitos peraluminosos propostos por Villaseca et al. (1998), baseado no diagrama A-B (Debon \& Le Fort, 1983), as amostras se distribuem dominantemente no campo dos granitos peraluminosos altamente félsicos (f-P). 
Tabela 1. Análises química de elementos maiores e traço do Granito Três Figueiras. LOI = perda ao fogo.

Table1. Chemical analysis of major and trace elements of Três Figueiras Granite. LOI = loss on ignition.

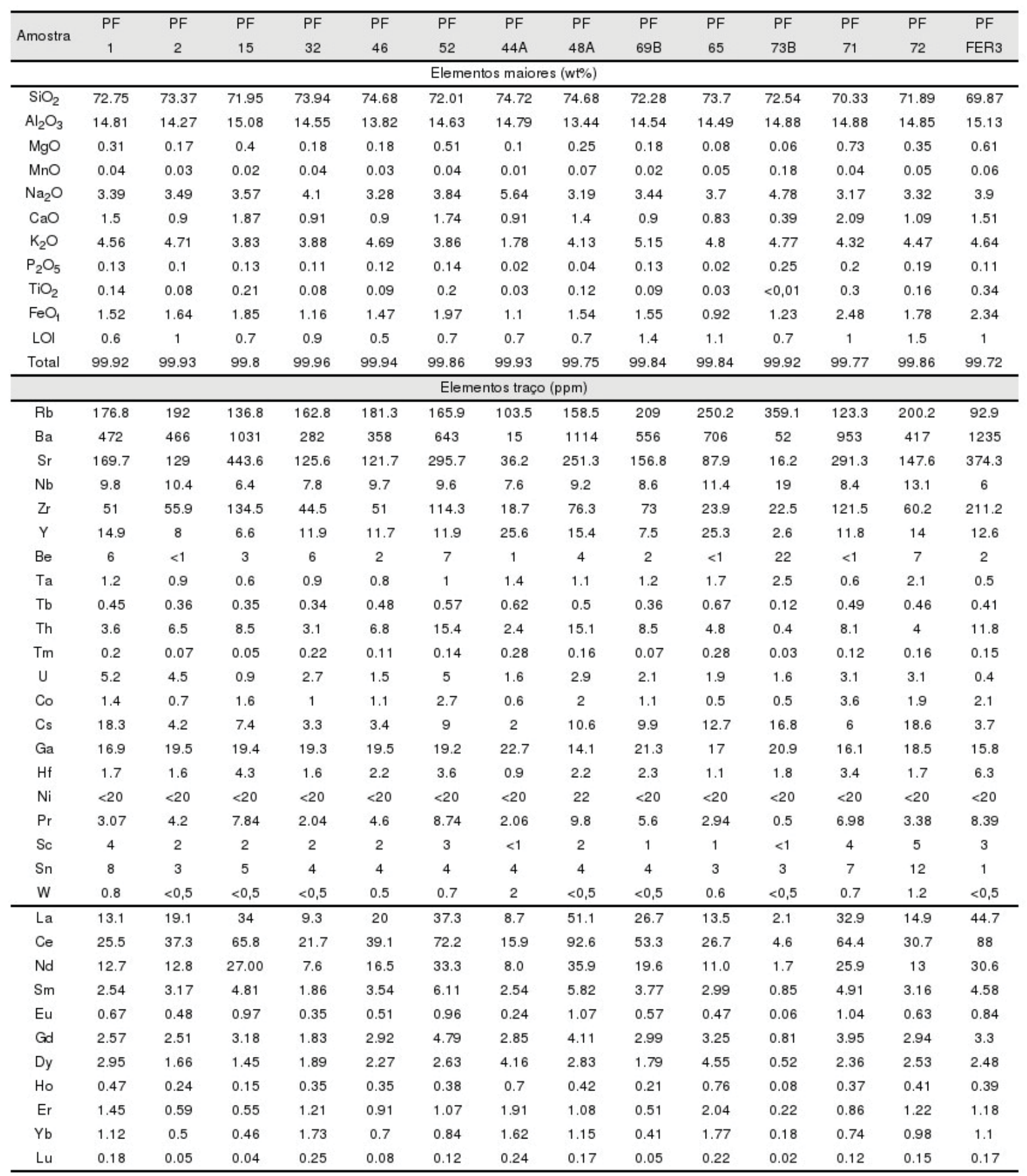

Nos diagramas de Harker, utilizando a $\mathrm{SiO}_{2}$ como índice de diferenciação, é possível observar trends de correlação negativos com aumento da diferenciação para a maioria dos elementos maiores (Fig. 13) como $\mathrm{Al}_{2} \mathrm{O}_{3}, \mathrm{MgO}, \mathrm{CaO}, \mathrm{TiO}_{2}, \mathrm{P}_{2} \mathrm{O}_{5}, \mathrm{FeO}$, evidenciando que o processo de cristalização fracionada foi importante na formação destes granitos. Os trends formados possivelmente refletem o fracionamento na cristalização de minerais como a biotita, plagioclásio e apatita. Este fator está relacionado com a diferenciação magmática, por exemplo a biotita, que ocorre como fase principal nos termos menos evoluídos (69-72\% de $\mathrm{SiO}_{2}$ ) e como acessório nos mais diferenciados (> $72 \%$ $\mathrm{SiO}_{2}$ ).

Para os elementos traços (Fig. 14), Ba, Sr, $\mathrm{Zr}$, La e Ce definem trends de correlação negativos com a diferenciação, de modo a refletir o fracionamento de minerais acessórios como zircão ( $\mathrm{Zr}$ ) e monazita (La e Ce).

Os diagramas multielementares normalizados para o ORG (granitos de dorsal oceânica), se- 
Tabela 2. Norma CIPW para as amostras estudadas. Legenda: $\mathrm{Q}=$ quartzo; $\mathrm{C}=$ coríndon; $\mathrm{Or}=$ ortoclásio; $\mathrm{Ab}=\mathrm{albita} ; \mathrm{An}=\mathrm{anor}-$ tita; $\mathrm{Hy}=$ hiperstênio; $\mathrm{Mt}=$ magnetita; $\mathrm{Il}=$ ilmenita; $\mathrm{Hm}=\mathrm{Hm}=$ hematita; $\mathrm{Ru}=$ rutilo; $\mathrm{Ap}=$ apatita.

Table 2. CIPW norm from the studied samples. Legend: $Q=$ quartz; $C=$ corundum; Or = orthoclase; $A b=$ albite; $A n=$ anorthite; $H y$ = hypersthene; $\mathrm{Mt}=$ magnetite; $\mathrm{Il}=$ ilmenite; $\mathrm{Hm}=$ hematite; $\mathrm{Ru}=$ rutile; $\mathrm{Ap}=$ apatite .

\begin{tabular}{ccccccccccccc}
\hline Amostra & $Q$ & $C$ & Or & $A b$ & $A n$ & $H y$ & $M t$ & $I l$ & $H m$ & $R u$ & $A p$ & Total \\
\hline PF01 & 32.27 & 1.88 & 26.95 & 28.69 & 6.59 & 0.77 & 0 & 0.09 & 1.69 & 0.1 & 0.31 & 99.33 \\
PF02 & 33.14 & 2.03 & 27.84 & 29.53 & 3.81 & 0.42 & 0 & 0.06 & 1.82 & 0.05 & 0.24 & 98.95 \\
PF15 & 32.29 & 1.97 & 22.63 & 30.21 & 8.43 & 1 & 0 & 0.04 & 2.05 & 0.19 & 0.31 & 99.12 \\
PF32 & 33.33 & 2.21 & 22.93 & 34.69 & 3.8 & 0.45 & 0 & 0.09 & 1.29 & 0.04 & 0.26 & 99.09 \\
PF46 & 35.79 & 2 & 27.72 & 27.75 & 3.68 & 0.45 & 0 & 0.06 & 1.63 & 0.06 & 0.28 & 99.43 \\
PF52 & 30.81 & 1.31 & 22.81 & 32.49 & 7.72 & 1.27 & 0 & 0.09 & 2.19 & 0.16 & 0.33 & 99.17 \\
PF44A & 33.06 & 1.98 & 10.52 & 47.72 & 4.38 & 0.25 & 0 & 0.02 & 1.22 & 0.02 & 0.05 & 99.22 \\
PF48A & 37.06 & 1.27 & 24.41 & 26.99 & 6.68 & 0.62 & 0 & 0.15 & 1.71 & 0.04 & 0.1 & 99.03 \\
PF69B & 30.73 & 1.98 & 30.44 & 29.11 & 3.62 & 0.45 & 0 & 0.04 & 1.72 & 0.07 & 0.31 & 98.46 \\
PF65 & 31.97 & 1.75 & 28.37 & 31.31 & 3.99 & 0.2 & 0.08 & 0.06 & 0.97 & 0 & 0.05 & 98.72 \\
PF73B & 26.26 & 1.74 & 28.19 & 40.45 & 0.3 & 0.15 & 0.59 & 0 & 0.96 & 0 & 0.59 & 99.23 \\
PF71 & 30.36 & 1.67 & 25.53 & 26.82 & 9.06 & 1.82 & 0 & 0.09 & 2.75 & 0.26 & 0.47 & 98.82 \\
PF72 & 33.15 & 3.02 & 26.42 & 28.09 & 4.17 & 0.87 & 0 & 0.11 & 1.98 & 0.1 & 0.45 & 98.36 \\
PFFER3 & 25.59 & 1.21 & 27.42 & 33 & 6.77 & 1.52 & 0 & 0.13 & 2.6 & 0.27 & 0.26 & 98.78 \\
\hline
\end{tabular}

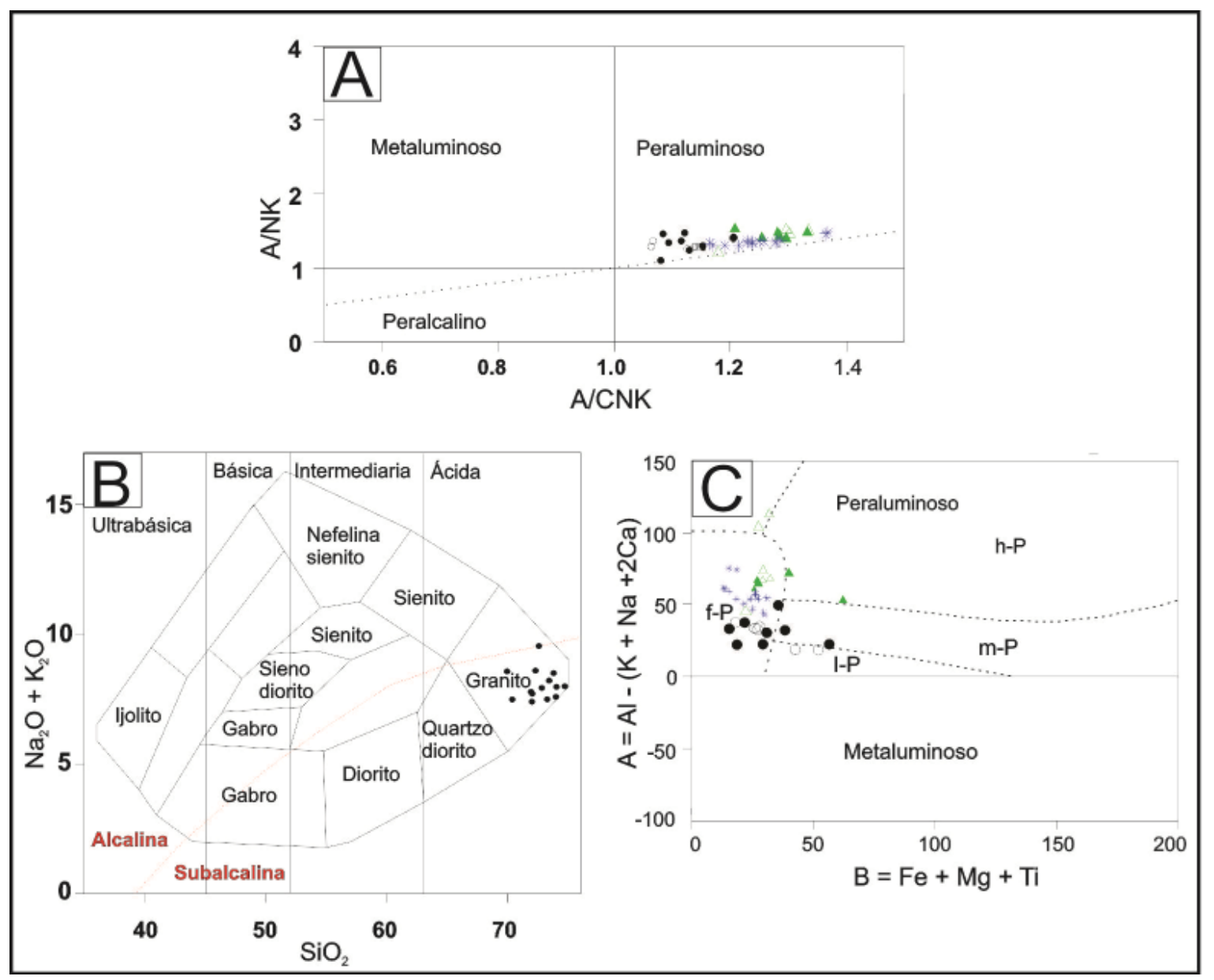

Figura 12. Diagramas de classificação para granitos. A) Diagrama de Shand (1943); B) Diagrama TAS (Cox et al., 1979); C) Diagrama de discriminação para granitos peraluminosos (modificado de Villaseca et al., 1998). Legenda: círculos vazados = Granito Três Figueiras indeformado; círculos preenchidos = Granito Três Figueiras deformado; triângulos preenchidos = Granito Cordilheira; triângulos vazados = granitos Hercinianos (oeste da França); asteriscos = Granito Arroio Francisquinho.

Figure 12. Granite classification diagrams. A) Diagram of Shand (1943); B) TAS Diagram (Cox et al., 1979;. C) Discrimination diagrams for peraluminous granites (modified from Villaseca et al., 1998). Legend: unfilled circles = undeformed Três Figueiras Granite; filled circles = deformed Três Figueiras Granite; filled triangles = Cordilheira Granite; unfilled triangles = Hercinian granites (Western France); asterisks = Arroio Francisquinho Granite . 


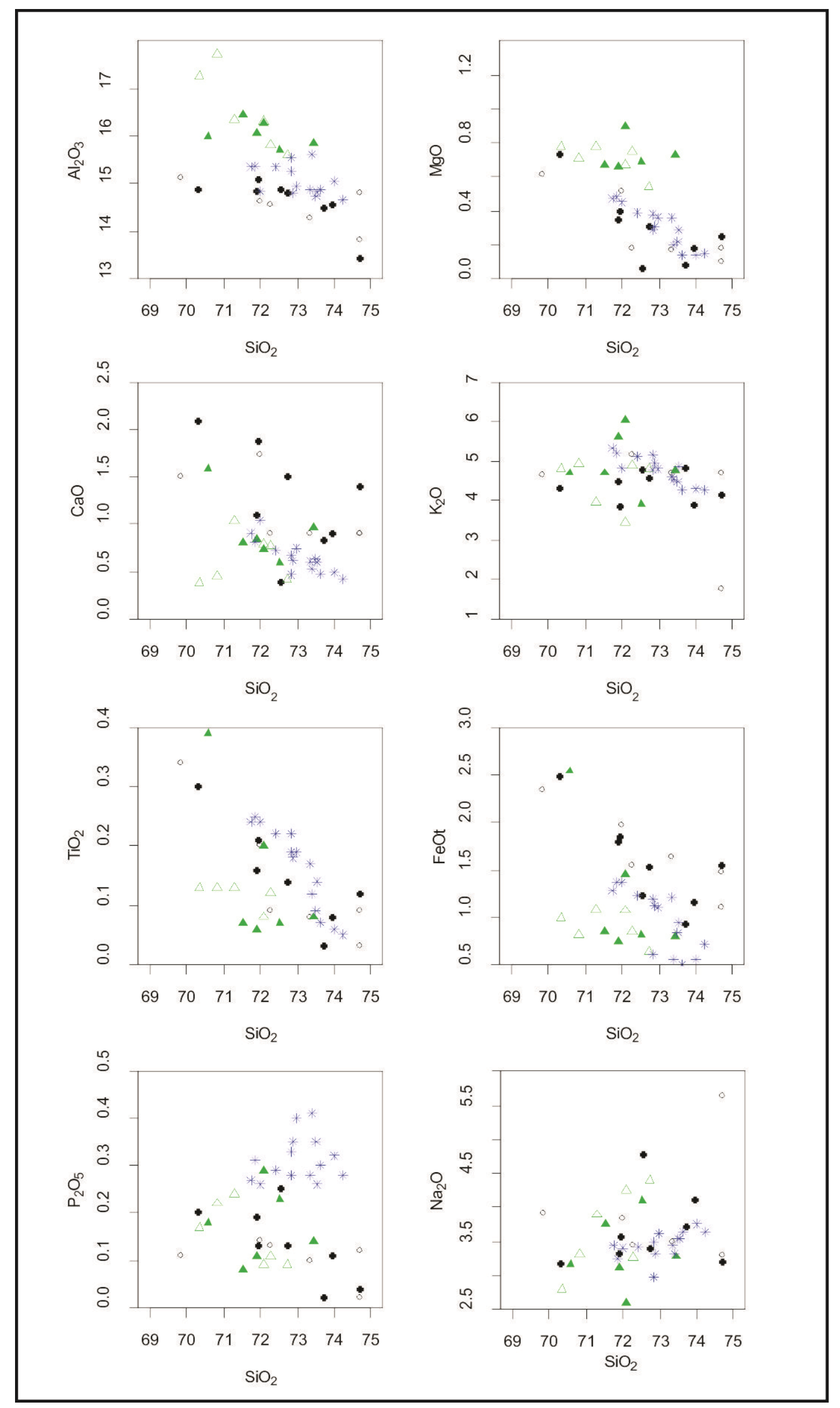

Figura 13. Diagramas Harker para os elementos maiores (símbolos conforme Fig. 12). Figure 13. Harker diagrams for major elements (symbols as in Fig. 12). 


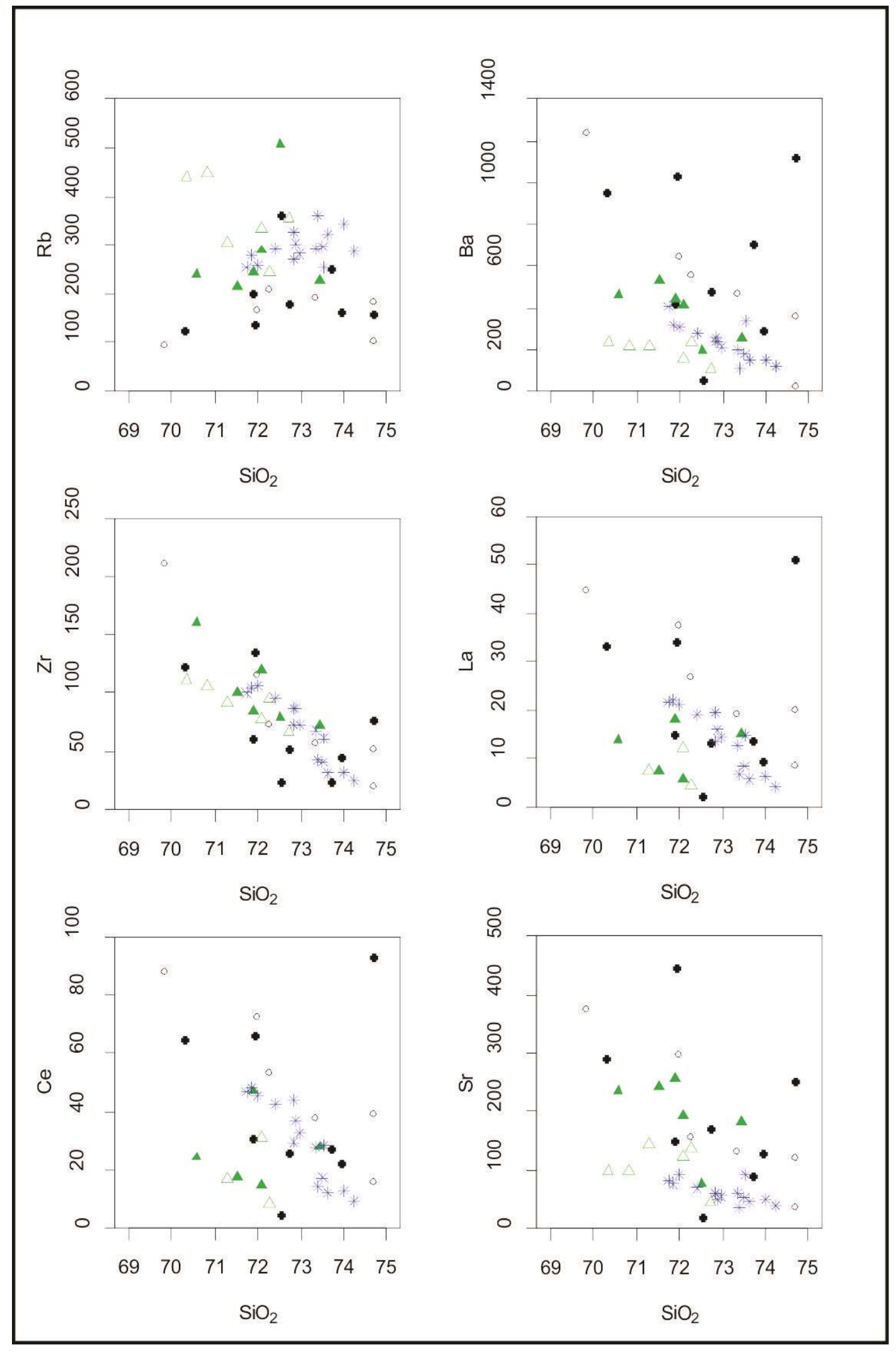

Figura 14. Diagramas Harker para os elementos traço (símbolos como na Fig. 12). Figure 14. Harker diagrams for trace elements (symbols as in Fig. 12). 
gundo os valores de Pearce et al. (1984) (Fig. 15A), apresentam um enriquecimento dos elementos litófilos de grande raio iônico (LILE) em relação aos elementos terras raras leves (LREE), com padrões semelhantes aos de granitos de ambientes sincolisionais. Quando normalizados para os valores condríticos de Thompson et al. (1982) (Fig. 15B) mostram um enriquecimento de elementos como $\mathrm{U}$, Th e Rb, e anomalias negativas para o $\mathrm{Nb}, \mathrm{Sr}$, Ti e P.

Os padrões dos elementos terras raras (ETR)

(Fig. 15C) quando normalizados para valores con- dríticos (Boynton, 1984) mostram um empobrecimento dos ETR leves em relação aos pesados, com padrões côncavos e leve anomalia negativa de Eu, o que indica a presença de plagioclásio no resíduo. Pode-se observar ainda uma inversão nos teores dos ETR, de modo que os leves tendem a se concentrar nos termos mais diferenciados, enquanto os pesados são mais abundantes nos termos menos diferenciados. 0 enriquecimento de ETR leves, especialmente Ce e La, indicam a concentração de minerais ricos nestes elementos, como granada e

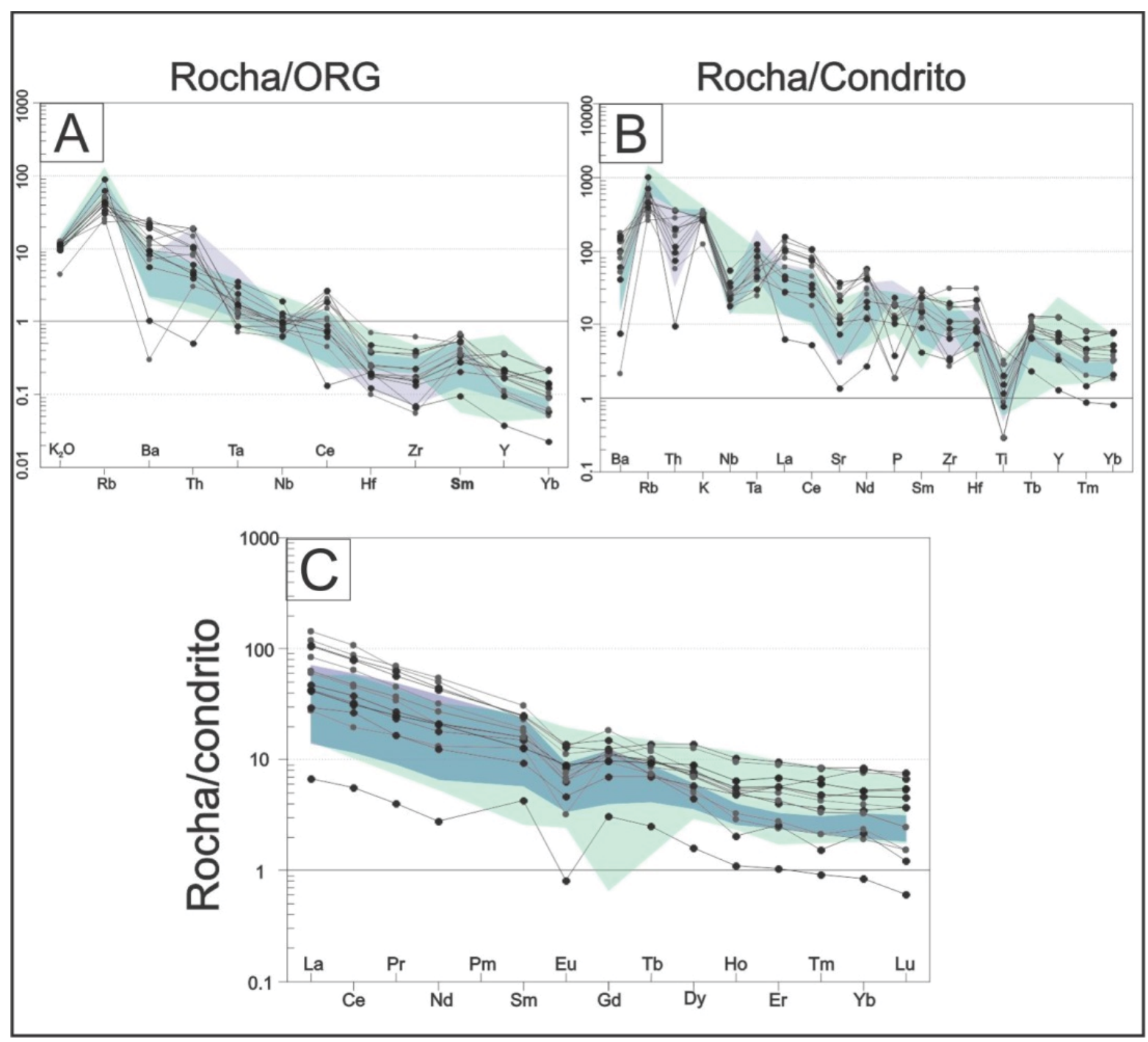

Figura 15. Aranhogramas. A) Diagrama normalizado para ORG, segundo valores de Pearce et al. (1984); B) Diagrama normalizado para o condrito, segundo os valores de Thompson et al. (1982); C) Diagrama normalizado para os valores condríticos de Boynton (1984). Linhas Pretas = Granito Três Figueiras indeformado; Linhas cinza = Granito Três Figueiras deformado; Campo azul $=$ Granito Cordilheira; Campo verde $=$ Granito Arroio Francisquinho; Campo roxo $=$ Granitos Hercinianos do Oeste da França.

Figure 15. Spidergrams. A) ORG-normalized diagram (values from Pearce et al., 1984); B) Chondrite-normalized diagram (values from Thompson et al., 1982); C) Chondrite-normalized diagram (values from Boynton, 1984). Grey lines = undeformed Três Figueiras Granite. Black lines = Deformed Três Figueiras Granite. Green field =Cordilheira Granite. Blue field = Arroio Francisquinho Granite. Purple field = Hercynian Granites from western France. 

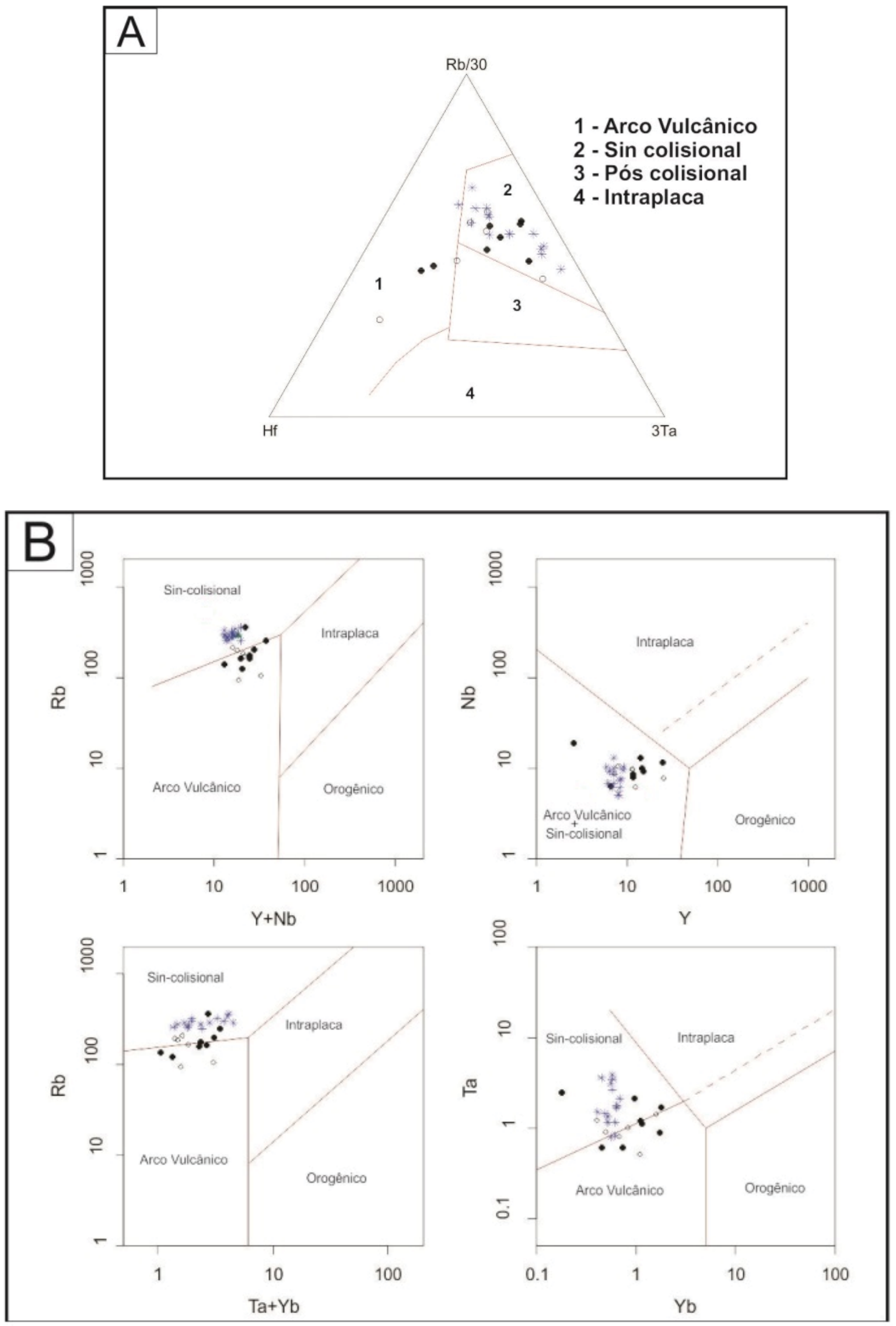

Figura 16. Diagramas de discriminação tectônica. A) Diagramas de Pearce et al. (1984); B) Diagrama de Harris et al. (1986) (símbolos como na Fig. 12).

Figure 16. Tectonic discrimination diagrams. A) Diagram of Pearce et al. (1984); B) Diagram of Harris et al. (1986) (symbols as in Fig. 12). 
Tabela 3. Dados analíticos U-Pb para os zircões do Granito Três Figueiras. Apenas os spots em itálico e negrito foram utilizados no cálculo da idade magmática.

Table 3. U-Pb analytical data of zircons from Três Figueiras Granite. Only italic and bold spots where used for magmatic age calculation.

\begin{tabular}{|c|c|c|c|c|c|c|c|c|}
\hline Spot & $\begin{array}{c}P F \\
01-1.1\end{array}$ & $\begin{array}{c}P F \\
01-2.1\end{array}$ & $\begin{array}{c}P F \\
01-3.1\end{array}$ & $\begin{array}{c}\text { PF } \\
01-6.1\end{array}$ & $\begin{array}{c}P F \\
01-7.1\end{array}$ & $\begin{array}{c}\text { PF } \\
01-8.1\end{array}$ & $\begin{array}{c}\text { PF } \\
01-9.1\end{array}$ & $\begin{array}{c}\text { PF } \\
01-11.1\end{array}$ \\
\hline $206 \mathrm{~Pb}(\%)$ & 3.48 & 3.84 & 0.99 & 3.84 & 0.35 & 2.74 & 0.3 & 4.82 \\
\hline $\mathrm{U}(\mathrm{ppm})$ & 856 & 352 & 37 & 373 & 212 & 225 & 875 & 1439 \\
\hline Th (ppm) & 132 & 217 & 57 & 101 & 63 & 34 & 59 & 54 \\
\hline $232 \mathrm{Th} /{ }^{238} \mathrm{U}$ & 0.16 & 0.64 & 1.61 & 0.28 & 0.31 & 0.16 & 0.07 & 0.04 \\
\hline $\begin{array}{c}207 c \text { orrigido } \\
206 \mathrm{~Pb} /{ }^{238} \mathrm{U} \\
\text { (idade) }\end{array}$ & 604 & 558.1 & 600.1 & 915.2 & 583 & 950.5 & 767.2 & 652.4 \\
\hline 1s (erro) & 8.6 & 9.6 & 10.8 & 14.6 & 8.3 & 16.5 & 10.5 & 10.3 \\
\hline $\begin{array}{l}204 \text { corrigido } \\
207 \mathrm{~Pb} /{ }^{206} \mathrm{~Pb} \\
\text { (idade) }\end{array}$ & 595 & 583 & 544 & 1295 & 559 & 1310 & 833 & 1028 \\
\hline 1s (erro) & 160 & 218 & 113 & 120 & 53 & 99 & 18 & 169 \\
\hline $\begin{array}{c}\% \\
\text { discordância }\end{array}$ & -1 & 5 & -9 & 40 & -4 & 36 & 8 & 56 \\
\hline $207 \mathrm{~Pb} /{ }^{235} \mathrm{U}$ & 0.81 & 0.74 & 0.78 & 1.79 & 0.77 & 1.88 & 1.17 & 1.09 \\
\hline$\%$ erro & 7.5 & 10.2 & 5.5 & 6.4 & 2.9 & 5.4 & 1.6 & 8.5 \\
\hline $206 \mathrm{~Pb} /{ }^{238} \mathrm{U}$ & 0.098 & 0.09 & 0.097 & 0.155 & 0.095 & 0.161 & 0.127 & 0.108 \\
\hline$\%$ erro & 1.4 & 1.7 & 1.8 & 1.5 & 1.5 & 1.7 & 1.4 & 1.5 \\
\hline erro corrigido & 0.189 & 0.168 & 0.336 & 0.241 & 0.517 & 0.32 & 0.854 & 0.173 \\
\hline
\end{tabular}

monazita. Os padrões observados são uniformes para todo conjunto de amostras, o que indica uma fonte comagmática e homogênea para o GTF. Os padrões côncavos observados sugerem um magma gerado a partir da fusão de rochas quartzo-feldspáticas com anfibólio no resíduo.

Nos diagramas de Pearce et al. (1984) (Fig. $16 \mathrm{~A})$ as amostras plotam dominantemente na interface entre os granitos sincolisionais e granitos de arco vulcânico. No diagrama de Harris et al. (1986) (Fig. 16B), que diferencia granitos de arco vulcânico, intraplaca e distinguem os granitos colisionais em sin- e pós-colisionais, as amostras posicionam-se dominantemente no campo de granitos sincolisionais.

Para fins de comparação e discussão, foi realizada uma compilação de dados geoquímicos com granitos da Suíte Granítica Cordilheira (SGC) do Cinturão Dom Feliciano, extraído de Koester et al. (2001b), bem como dos granitos Hercinianos do Oeste da França, extraído de Tartèse \& Boulvais (2010).

De modo geral o GTF apresenta teores mais baixos de $\mathrm{Al}_{2} \mathrm{O}_{3}, \mathrm{MgO}$ e $\mathrm{Rb}$ e teores mais elevados de CaO, La e Ce. As rochas da Suíte Granítica Cordilheira apresentam maiores dispersões para os elementos maiores em diagramas de Harker e padrões mais variados nos diagramas multielementares, o que reflete diferentes fontes e processos na evolução destes granitos. A cristalização fracionada é a principal diferença, sendo um processo importante para o GTF e não tendo expressividade na evolução magmática dos demais granitos da Suíte Granítica Cordilheira (Koester et al., 2001b). Quimicamente, o GTF é semelhante aos granitos Hercinianos do oeste da França, apresentando correlações negativas com a diferenciação para a maioria dos elementos, bem como padrões semelhantes em diagrama de ETR.

Com relação às possíveis fontes, Philipp et al. (2013), com base nas diferenças composicionais observadas no grupo de amostras analisado, sugerem para o GTF uma fonte quartzofeldspática. Os dados obtidos neste trabalho, com padrões semelhantes e uniformes para todo grupo de amostras, sugere uma fonte única e homogênea para o GTF. Para as demais rochas da Suíte Granítica Cordilheira, Philipp et al. (2013), 
com base em modelamentos petrogenéticos, sugerem como fonte as rochas metapelíticas da Suíte Metamórfica Várzea do Capivarita, com temperaturas de fusão da ordem $740 \sim 820{ }^{\circ} \mathrm{C}$ para o Granito Cordilheira e $760 \sim 815{ }^{\circ} \mathrm{C}$ para o Granito Arroio Francisquinho. Koester et al. (2002), por meio de petrologia experimental, demonstram que a Suíte Metamórfica Várzea do Capivarita pode ser uma possível fonte, entretanto não é a mais provável fonte para a Suíte Granítica Cordilheira, indicando como processos e fontes alternativas (i) líquidos anatéticos, representados por diferentes fusões da mesma fonte; (ii) líquidos anatéticos diferentes, gerados de diferentes fontes ou (iii) líquidos anatéticos gerados em condições diferentes de pressão, temperatura e fluidos.

\subsection{Geocronologia}

Os resultados das análises em U-Pb SHRIMP para os zircões do GTF são apresentados na tabela 3 e as imagens de catodoluminescência com a localização dos pontos analisados podem ser visualizados na figura 17.

A amostra analisada corresponde ao ponto PF 01. A maioria dos cristais de zircão varia de 50 a $250 \mu \mathrm{m}$ e possuem zonação interna, sendo possível observar núcleos mais claros e bordas mais escuras. Os pontos analisados foram efetuados nas bordas dos cristais. A maioria dos cristais apresentam as extremidades bipiramidais, com minoria de cristais arredondados. As amostras apresentam conteúdo variado de urânio (37 - 875 ppm) com razões $\mathrm{Th} / \mathrm{U}$ moderadas a altas $(0,16-1,61)$. Algumas amostras apresentaram discordâncias e não foram utilizadas no cálculo da idade, devido a possíveis perdas ou ganhos de $\mathrm{Pb}$ no sistema. As amostras foram plotadas em um diagrama concórdia (Fig. 17). Nela, é possível visualizar uma concentração de pontos próximo à concórdia, caracterizado por 4 grãos de zircão, os quais sugerem uma idade de cristalização magmática de $585 \pm 16$ Ma. Os resultados dos zircões discordantes são interpretados como zircões herdados e tem idade variando de 833 a 1.310 Ma.

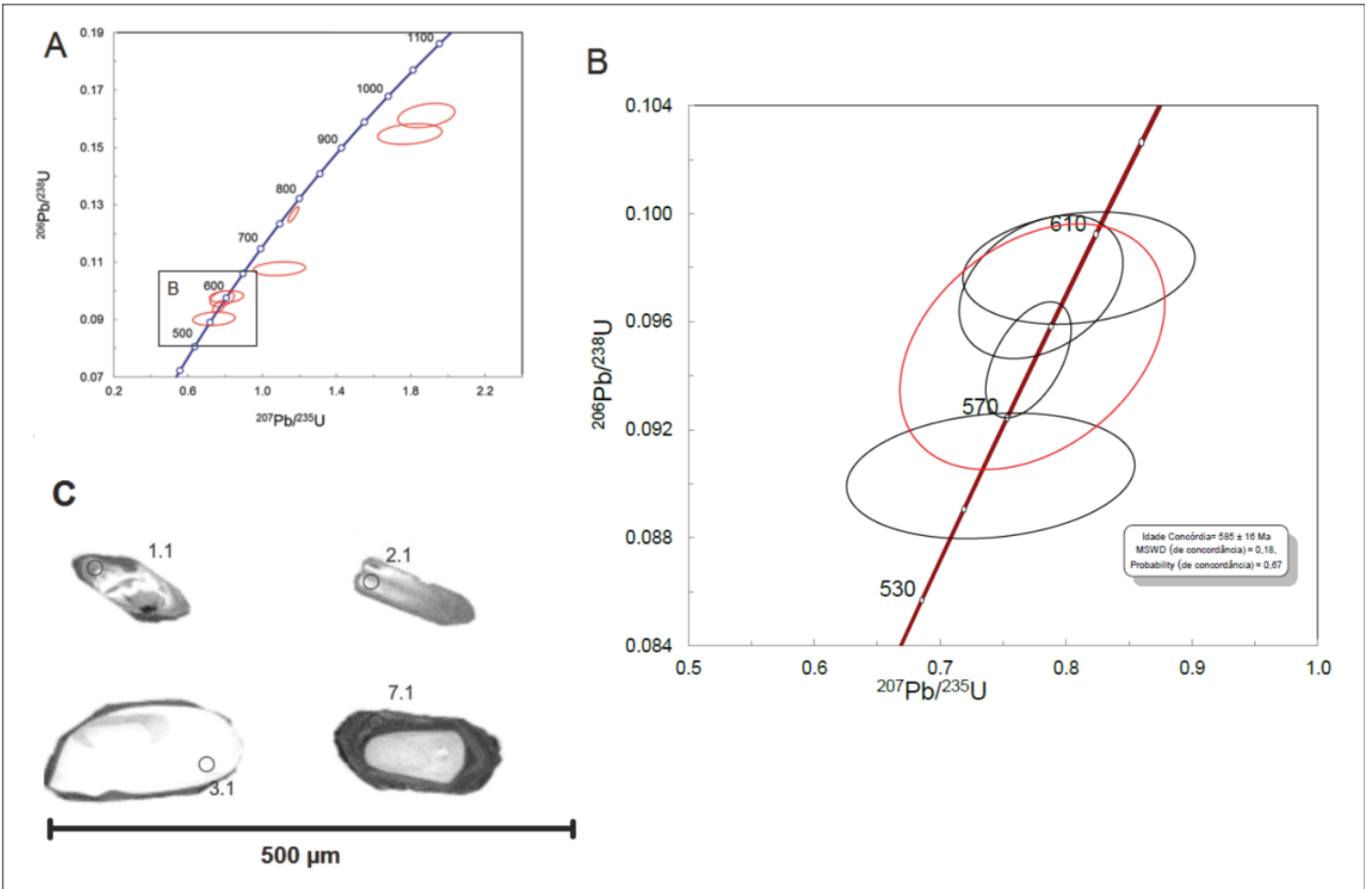

Figura 17. Idade U-Pb SHRIMP do Granito Três Figueiras. A) Imagens de catodoluminescência dos zircões utilizados no cálculo da idade magmática; B) Diagrama concórdia do Granito Três Figueiras, mostrando todos os pontos analisados; C) Detalhe do diagrama concórdia apenas com os pontos analíticos utilizados no cálculo da idade magmática de $585 \pm 16$ Ma do Granito Três Figueiras.

Figure 17. U-Pb SHRIMP age of Três Figueiras Granite. A) Cathodoluminescence image from zircons used on the magmatic age calculation; B) Concordia diagram of Três Figueiras Granite showing analyzed points; C) Detail of Concordia diagram showing only the calculated points of the $585 \pm 16$ Ma magmatic age. 


\section{Conclusões}

Considerando os aspectos de campo e o conjunto de dados petrográficos, mineralógicos e químicos, o Granito Três Figueiras se encaixa nos granitos MPG da literatura, sendo um granito peraluminoso com duas micas com presença de granada, turmalina e monazita como principais fases acessórias.

O Granito Três Figueiras é um granito sintectônico à Zona de Cisalhamento Arroio Grande, uma zona de cisalhamento transcorrente subvertical com direção principal W-SW-ENE, com caimento para SE. Associado a essa foliação, apresenta uma lineação de estiramento do quartzo, sub-horizontal com sentido de caimento para ENE.

$O$ conjunto de texturas e estruturas impressos neste granito demonstram que o resfriamento do magma é acompanhado pela progressão da deformação, em condições de fácies anfibolito inferior a médio, a temperaturas de pelo menos $550^{\circ} \mathrm{C}$.

0 Granito Três Figueiras é um granito peraluminoso com teores $\mathrm{A} / \mathrm{CNK}$ entre 1,07 e 1,21 e coríndon normativo entre 1,2 e $3 \%$, sendo o principal processo de evolução magmática a cristalização fracionada de minerais como biotita, plagioclásio, granada, monazita, apatita e zircão. Os diagramas ETR mostram que este granito possui uma fonte homogênea, provavelmente quartzo-feldspática com anfibólio no resíduo.

As principais diferenças deste granito aos demais da Suíte Granítica Cordilheira são teores mais elevados de $\mathrm{CaO}$, La e Ce e mais baixos de $\mathrm{Al}_{2} \mathrm{O}_{3}, \mathrm{MgO}$ e Rb, bem como padrões mais homogêneos e uniformes em diagramas multielementares e menos dispersos em diagramas de Harker, o que sugere fontes e processos distintos para estes granitos. Quimicamente são semelhantes aos granitos Hercinianos do oeste da França, interpretados como produto de anatexia crustal por fusão parcial, com principal mecanismo de evolução a cristalização fracionada. Segundo Barbarin (1999) os granitos do tipo MPG ocorrem onde a crosta continental é cortada por zonas de cisalhamento e/ ou cavalgamento. Estudos experimentais observados na revisão realizada por Weinberg \& Hasalova (2015) confirmam que os leucogranitos a duas mi- cas cristalizam em locais com maior fugacidade de água. 0 conteúdo inicial de água nos fundidos para os leucogranitos com cordierita não passam de 4 $\%$, enquanto deve-se atingir aproximadamente 7 a $8 \%$ para precipitar muscovita. Esta água estaria relacionada à Zona de Cisalhamento Arroio Grande que, quando ativa, canalizou os fluidos na crosta. Estes fluidos não apenas lubrificaram a zona de cisalhamento como também promoveram extensiva fusão crustal na região.

A idade de cristalização magmática de 585 \pm 16 Ma sugere um evento de fusão crustal mais recente em relação aos demais granitoides da Suíte Granítica Cordilheira (630 - $617 \mathrm{Ma}$ ), demonstrando a existência de dois eventos distintos de movimentação transcorrente no leste do Cinturão Dom Feliciano, cinemática e idades distintas, mas ambos marcados por granitoides peraluminosos do tipo MPG.

Agradecimentos. Agradecemos aos editores da revista, Paulo A. de Souza e Lauro V.S. Nardi e a revisora do manuscrito Valderez Pinto Ferreira. Ao Centro de Pesquisas Geocronológicas (CPGeo) da USP pelo apoio com as análises de U-Pb SHRIMP, em especial a Kei Sato. Ao CNPq pelo auxílio e bolsa concedida a Fernando Galvão Klein (processo ${ }^{\circ}$ 132809/2013-3) e pelo Projeto Universal (processo $\mathrm{n}^{\circ} 480135 / 2013-4$ ).

\section{Referências bibliográficas}

Barbarin, B. 1990. Granitoids: main petrogenetic classifications in relation to origin and tectonic setting. Geology Journal, 25: 227-238.

Barbarin, B. 1996. Genesis of the two main types of peraluminous granitoids. Geology, 24(4): 295298.

Barbarin, B. 1999. A review of the relationships between granitoid types, their origins and their geodynamic environments. Lithos, 46: 605-626.

Bitencourt, M.F. \& Nardi, L.V.S. 1986. Metamorfismo e deformação dúctil de rochas graníticas. Acta Geológica Leopoldensia, 11(23): 33-56.

Bitencourt, M.F. \& Nardi, L.V.S. 2000. Tectonic setting and sources of magmatism related to the Southern Brazilian Shear Belt. Revista Brasileira de Geociências, 30(1): 186-189. 
Black, L.P., Kamo, S.L., Allen, C.M., Davis, D.W., Aleinikoff, J.N., Valley, J.W., Mundil, R., Campbell, I.H., Korsch, R.J., Williams, I.S. \& Foudoulis, C. 2004. Improved $206 \mathrm{~Pb} / 238 \mathrm{U}$ microprobe geochronology by the monitoring of a trace-element related matrix effect; SHRIMP, ID-TIMS, ELA-ICP-MS and oxygen isotope documentation for a series of zircon standards. Chemistry Geology, 205: 115-140.

Boynton, W.V. 1984. Geochemistry of the rare earth elements: meteorite studies. In: Henderson, P. (Ed.). Rare-Earth Element Geochemistry. Amsterdã, Elsevier, p. 63-114.

Chappell, B.W. \& White, A.J.R. 1974. Two contrasting granite types. Pacific Geology, 8: 174-184.

Chappell B.W. \& White A.J.R. 1992. I-Type and SType granites in the Lachlan Fold Belt. Transaction Royal Society, 83: 1-26.

Cox, K.G., Bell, J.D. \& Pankhurst, R.J. 1979. The Interpretation of Igneous Rocks. Londres, George Allen \& Unwin, 450 p.

De La Roche, H., Leterrier, J., Grandclaude, P. \& Marchal, M. 1980. A classification of volcanic and plutonic rocks using R1R2-diagram and major element analyses - its relationships with current nomenclature. Chemical Geology, 29: 183-210.

Debon, F. \& Le Fort, P. 1983. A chemical-mineralogical classification of common plutonic rocks and associations. Earth Sciences, 73: 135-149.

Fernandes, L.A.D., Menegat, R., Costa, A.F.U., Koester, E., Kramer, G., Tommasi, A., Porcher, C.C., Ramgrab, G.E. \& Camozzato, E. 1995. Evolução tectônica do Cinturão Dom Feliciano no Escudo Sul-rio-grandense: Parte II - uma contribuição a partir das assinaturas geofísicas. Revista Brasileira de Geociências, 25: 375-384.

Fragoso-Cesar, A.R.S., Figueiredo, M.C.H., Soliani Jr., E. \& Faccini, U.F. 1986. O Batólito Pelotas (Proterozóico Superior/Eo-Paleozóico) no Escudo do rio Grande do Sul. In: CONGRESSO BRASILEIRO DE GEOLOGIA, 34, 1986, Goiânia. Anais... Goiânia, SBG, v. 3, p. 13-22

Frantz, J.C., McNaughton, N.J., Marques, J.C., Hartmann, L.A., Botelho, N.F. \& Caravaca, G. 2003. SHRIMP U-Pb zircon ages of granitoids from southernmost Brazil: constrains on the temporal evolution of the Dorsal de Canguçu trans- current Shear Zone and Eastern Dom Feliciano Belt. In: SOUTH AMERICAN SYMPOSIUM ON ISOTOPE GEOLOGY IV, Salvador Short Papers, v. 1, p. 174-177.

Harris, N.B.W., Pearce, J.A. \& Tindle, A.G. 1986. Geochemical characteristics of collision zone magmatism. In: Coward, M.P., Ries, A.C. (Eds.). Collision Tectonics. Geological Society of London, Special Paper, 19: 115-158.

Heilbron, M., Pedrosa-Soares, A.C., Campos Neto, M., Silva, L.C. \& Trouw, R.A.J. 2004. A Província Mantiqueira. In: Mantesso Neto, A., Bartorelli, A., Carneiro, C.D.R., Brito Neves, B.B. (Eds.). $O$ desvendar de um continente: a moderna geologia da América do Sul e o legado da obra de Fernando Flávio Marques de Almeida. São Paulo, Beca, p. 203-234.

Janoušek, V., Farrow, C.M. \& Erban, V. 2006. Interpretation of whole-rock geochemical data in igneous geochemistry: introducing Geochemical Data Toolkit (gcdkit). Journal of Petrology, 47(6): 1255-1259.

Klein, F.G. 2012. Petrologia do Granito Três Figueiras, Arroio Grande, RS. Porto Alegre, 69 p. Monografia de Conclusão de Curso, Curso de Geologia, Instituto de Geociências, Universidade Federal do Rio Grande do Sul.

Koester, E. 1995. Petrologia e geocronologia dos granitóides sintectônicos à Zona de Cisalhamento Dorsal de Canguçu. Porto Alegre, 240 p. Dissertação de Mestrado, Programa de Pós-graduação em Geociências, Instituto de Geociências, Universidade Federal do Rio Grande do Sul.

Koester, E., Fernandes, L.A.D., Soliani Jr., E., Kraemer, G., Nardi, L.V.S. \& Roisemberg, A. 2001a. Geologia e geoquímica dos granitóides sintectônicos à Zona de Cisalhamento Transcorrente Dorsal de Canguçu, Encruzilhada do Sul, RS. Revista Brasileira de Geociências, 31(2): 141-154.

Koester, E., Roisenberg, A., Fernandes, L.A.D., Soliani Jr., E., Nardi, L.V.S. \& Kraemer, G. 2001 b. Petrologia dos granitóides sintectônicos à Zona de Cisalhamento Transcorrente Dorsal de Canguçu, Encruzilhada do Sul, RS. Revista Brasileira de Geociências, 31(2): 131-140.

Koester, E., Pawley, A.R., Fernandes, L.A.D., Porcher, C.C. \& Soliani Jr., E. 2002. Experimental melting of cordierite gneiss and the petrogenesys of 
syntranscurrent peraluminous granites in the southern Brazil. Journal of Petrology, 48(43): 1595-1616.

Lameyre, J., 1980. Les magmas granitiques: leurs comportements, leurs associations et leurs sources. Mémories de la Société Géologique France, 10: 51-62.

Le Fort, P. 1981. Manaslu lencogranite: a collision signature of the Himalaya. A model for its genesis and emplacement. Journal Geophysical Research, 86: 10545-10568.

Loureiro, P.0. 2013. Evolução Magmática do Complexo Pinheiro Machado na região de Monte Bonito, Pelotas, RS. Porto Alegre, 75p. Monografia de Conclusão de Curso, Curso de Geologia, Instituto de Geociências, Universidade Federal do Rio Grande do Sul.

Ludwig, K. R. 2003. User's manual for Isoplot 3.0: A geochronological toolkit for Microsoft Excel. Berkeley Geochronology Center, $71 \mathrm{p}$.

Machado, R., Philipp, R.P. \& Mello, F. 1995. Reconhecimento de zonas de cisalhamento dúcteis de alto ângulo com cinemática superposta na extremidade sul do Batólito Pelotas, RS. SIMPÓSIO NACIONAL DE ESTUDOS TECTÔNICOS, 5, 1995, Gramado, Boletim de Resumos Expandidos, p. 52-53.

Masquelin, H., Fernandes, L.A.D., Lenz, C., Porcher, C.C. \& McNaughton, N.J. 2012. The Cerro Olivo Complex: a pre-collisional Neoproterozoic magmatic arc in Eastern Uruguay. International Geology Review, 54: 1161- 1183.

Nardi, L.V.S. \& Frantz, J.C. 1995. The Cordilheira intrusive suite: late Proterozoic peraluminous granitoids from the southern Brazil. Journal of South American Earth Sciences, 8(1): 55-63.

Passchier, C.W. \& Trouw, R.A.J. 1996. Shear Zones. In: Passchier, C.W \& Trouwm R.A.J. (Eds.). Microtectonics. Berlim, Springer Verlag, p. 97-129.

Passchier, C.W. \& Trouw, R.A.J. 2005. Microtectonics. Berlim, Springer Verlag, $366 \mathrm{p}$.

Patiño-Douce, A.E. 1999. What do experiments tell us about the relative contributions of crust and mantle to the origin of granitic magmas? In: Castro, A., Fernandez, C., Vigneresse, J.E. (Eds.). Understanding Granites: New and Classical Techniques. Geological Society of London, Special Publications, 168: 55-75.
Pearce, J.A, Harris, N.W. \& Tindle, A.G. 1984. Trace element discrimination diagrams for the tectonic interpretation of granitic rocks. Journal of Petrology, 25: 956-983.

Pérez-Soba, C. \& Villaseca, C. 2010. Petrogenesis of highly fractionated I-type peraluminous granites: La Pedriza pluton (Spanish Central System). Geologica Acta, 8(2): 131-149.

Philipp, R.P. 1998. A evolução geológica e tectônica do Batólito Pelotas no Rio Grande do Sul. São Paulo, 255p. Tese de Doutorado, Programa de Pós-Graduação em Geociências, Instituto de Geociências, Universidade de São Paulo.

Philipp, R.P., Nardi, L.V.S. \& Bitencourt, M.F. 2000.0 Batólito Pelotas no Rio Grande do Sul. In: Holz, Michel, De Ros, L.F. (Org.). Geologia do Rio Grande do Sul. Porto Alegre, Ed. UFRGS, p. 133-160.

Philipp, R.P., Machado, R., Nardi, L.V.S. \& Lafon, J.M. 2002. O magmatismo granítico Neoproterozóico do Batólito Pelotas no sul do Brasil: novos dados e revisão de geocronologia regional. Revista Brasileira de Geociências, 32(2): 277-290.

Philipp, R.P., Massone, H.J \& Campos, R.S. 2013. Peraluminous leucogranites of the Cordilheira Suite: A record of Neoproterozoic collision and the generation of the Pelotas Batholith, Dom Feliciano Belt, Southern Brazil. Journal of South American Earth Sciences, 43: 08-24.

Pitcher, W.S. 1983. Granite: typology, geological environment and melting relationships. In: Atherton, M.P., Gribble, C.D. (Eds.). Migmatites, Melting and Metamorphism. Chechire, Shiva Publishing Limited, p. 277-287.

Ramos, R.C. \& Koester, E. 2014. Geologia da associação metamáfica-ultramáfica da região de Arroio Grande, sudeste do Escudo Sul-Rio-Grandense. Pesquisas em Geociências, 41(1): 25-38.

Ramos, R.C. \& Koester, E. 2015. Lithogeochemistry of the meta-igneous units from Arroio Grande Ophiolitic Complex, southernmost Brazil. Brazilian Journal of Geology, 45(1): 65-78.

Sawyer, E.W., Cesare, B. \& Brown, M. 2011. When the continental crust melts. Elements, 7: 227232.

Shand, S.J. 1943. Eruptive Rocks. Their Genesis, Composition, Classification, and Their Relation to Ore-Deposits with a Chapter on Meteorite. Nova Iorque, John Wiley \& Sons, 444 p. 
Silva, R.F. \& Koester, E. 2014. Petrologia do Granito Capão do Leão, Domínio Leste do Escudo Sul -Rio-Grandense, RS. In: CONGRESSO BRASILEIRO DE GEOLOGIA, 47, 2014, Salvador. Anais... Salvador, SBG, p. 860.

Streckeisen, A.L. 1976. Classification of the common igneous rocks by means of their chemical composition: a provisional attempt. Neuesjahrbuchfürmineralogie, 1: 1-15.

Tartèse, R. \& Boulvais, P. 2010. Differention of peraluminous leucogranites "en route" to the surface. Lithos, 114: 353-368

Thompson, R.N., Morrison, M.A., Hendry, G.L. \& Parry, S.J. 1982. An assessment of the relative roles of crust and mantle in magma genesis: an elemental approach. Philosophical Transactions Royal Society of London, 310: 549-590.

Tickyj, H., Hartmann, L.A., Vasconcellos, M., Philipp, R.P. \& Remus, M.V.D. 2004. Electron microprobe dating of monazite substantiates ages of major geological events in the southern Brazilian Shield. Journal of South American Earth Sciences, 16: 699-713.

Trainini, D.R. 1987. Projeto Mapas Metalogenéticos e de Previsão de Recursos Minerais, Folhas SI-22 Jaguarão-Rio Grande. Porto Alegre, Convênio DNPM/CPRM. 8 mapas. Escala 1:250.000

UFRGS, Universidade Federal do Rio Grande do Sul. 1972. Geologia das folhas de Arroio Grande, Erval, Basílio e Cerro Chato. Porto Alegre. Monografia de Conclusão de Curso de Graduação, Curso de Geologia, Universidade Federal do Rio Grande do Sul.

Vieira, D.T., Koester, E. \& Bertotti, A.L. 2016. Petrology of Chasqueiro Granite, Arroio Grande region, southeastern Sul-Rio-Grandense Shield. Brazilian Journal of Geology, 46(1): 49-78.

Villaseca, C., Barbero, L. \& Herreros, V. 1998. A re -examination of the typology of pera-luminous granite types in intracontinental orogenic belts. Transactions Royal Society Edinburgh, 89: 113119.

Weinberg, R.F. \& Hasalova, P. 2015. Water-fluxed melting of the continental crust: a review. $\mathrm{Li}^{-}$ thos, 212: 158-188.
White, A.J.R. \& Chappell, B.W. 1977. Ultrametamorphism and granitoid genesis. Tectonophysics, 43: 07-22.

White, A.J.R. \& Chappell, B.W. 1983. Granitoid types and their distribution in the Lachlan fold belt, southeast Australia. Geological Society of America Memoir, 159: 21-34.

Wildner, W., Ramgrab, G.E., Lopes, R.C. \& Iglesias, C.M.F. 2007. Mapa Geológico do Estado do Rio Grande do Sul. Brasília, CPRM - Serviço Geológico do Brasil. Escala 1:750.000.

Williams, I.S. 1998. U-Th-Pb geochronology by ion microprobe. In: McKibben, M.A., Shanks, W.C., Ridley, W.I. (Eds.). Applications of Microanalytical Techniques to Understanding Mineralizing Processes. Reviews in Economic Geology, 7: 1-35.

Wilson, M. 1989. Igneous Petrology. Londres, Unwin and Hyman, 466 p. 